\title{
Substantial effect of phytochemical constituents against the pandemic disease influenza-a review
}

\author{
A. Brindha Devi ${ }^{*}$ and R. Sarala
}

\begin{abstract}
Background: Influenza is an acute respiratory tract infection caused by the influenza virus. Vaccination and antiviral drugs are the two methods opted to control the disease. Besides their efficiency, they also cause adverse side effects. Hence, scientists turned their attention to powerful herbal medicines. This review put focus on various proven, scientifically validated anti-influenza compounds produced by the plants suggested for the production of newer drugs for the better treatment of influenza and its related antiviral diseases too.

Main body: In this review, fifty medicinal herb phytochemical constituents and their anti-influenza activities have been documented. Specifically, this review brings out the accurate and substantiates mechanisms of action of these constituents. This study categorizes the phytochemical constituents into primary and secondary metabolites which provide a source for synthesizing and developing new drugs.

Conclusion: This article provides a summary of the actions of the herbal constituents. Since the mechanisms of action of the components are elucidated, the pandemic situation arising due to influenza and similar antiviral diseases can be handled promisingly with greater efficiency. However, clinical trials are in great demand. The formulation of usage may be a single drug compound or multi-herbal combination. These, in turn, open up a new arena for the pharmaceutical industries to develop innovative drugs.
\end{abstract}

Keywords: Influenza, Medicinal herb, Phytochemical, Primary metabolite, Secondary metabolite, Drug

\section{Background}

Influenza virus infections remain a major formidable disease of man defying control. It is a widespread disease of man occurring in epidemics and pandemic forms [1]. Influenza severity varies from mild to extreme and is determined by the virus type and its host [2].

Influenza viruses belong to the Orthomyxoviridae family which comprises seven genera Alpha influenza virus, Beta influenza virus, Delta influenza virus, Gamma influenza virus, Isa virus, Quaranja virus, and Thogotovirus $[3,4]$. Influenza A, B, D, and C viruses belong to Alpha, Beta, Delta, and Gamma genera respectively.

\footnotetext{
*Correspondence: raghabrins@gmail.com

Department of Botany, Periyar EVR College (Autonomous), (Affiliated to Bharathidasan University, Trichy-24), Trichy-620 023, Tamil Nadu, India
}

Influenza A virus (IAV) hosted a wide range of species including wild aquatic birds, humans, poultry, pigs, horses, and sea mammals [5] which cause epidemics and pandemic conditions [6]. Influenza B virus (IBV) infects humans and seals $[5,7]$. Influenza $C$ virus (ICV) infections have been documented in humans and swine [5, 7]. Influenza $B$ and $C$ viruses create epidemics but lack pandemic potential [8]. Influenza D virus (IDV) infection was observed in farmed cattle, goats, pigs, and buffalo [9]. Serological evidence detects the presence of the virus in humans [10] but the investigation of transmission remains unclear $[7,11]$.

The World Health Organization (WHO) along with the National Influenza Centers (NIC) and Centers for Disease Control and Prevention (CDC) strengthen global influenza surveillance during every seasonal outbreak

\section{Springer Open}

(c) The Author(s). 2021 Open Access This article is licensed under a Creative Commons Attribution 4.0 International License, which permits use, sharing, adaptation, distribution and reproduction in any medium or format, as long as you give appropriate credit to the original author(s) and the source, provide a link to the Creative Commons licence, and indicate if changes were made. The images or other third party material in this article are included in the article's Creative Commons licence, unless indicated otherwise in a credit line to the material. If material is not included in the article's Creative Commons licence and your intended use is not permitted by statutory regulation or exceeds the permitted use, you will need to obtain permission directly from the copyright holder. To view a copy of this licence, visit http://creativecommons.org/licenses/by/4.0/. 
$[12,13]$. These authorized centers monitor global influenza circulation, detecting the emergence of new strains followed by the recommendation of vaccine usage [12, 13]. Many ongoing research activities like vaccine preparation, clinical trial of new drugs, and Traditional and Complementary medicine (T\&CM) using herbs are carried worldwide to anticipate their work. Traditional and Complementary medicine $(\mathrm{T} \& \mathrm{CM})$ role is indispensable for the prevention and management of chronic diseases [14] and WHO estimates $65-80 \%$ of the world population rely on it [15]. Interestingly, 34 countries include herbal medicines in their national essential medicines list (NEML) [14]. Hence, herbal medicines are always in great demand for the ailment of severe diseases.

This review article enlists several anti-influenza potential herbs along with their phytochemical constituents showing multi-targeted action against influenza. This study significantly provides experimentally validated phytoconstituents showing the evidence of efficacy against influenza.

\section{Main text}

\section{Influenza viruses-an overview}

Influenza viruses are spherical (100 $\mathrm{nm}$ in diameter) or filamentous (300 $\mathrm{nm}$ in length) in shape [16]. They have a central core surrounded by an envelope. The central core region has RNA segments covered with a nucleocapsid protein (NP). The entire core is surrounded by a matrix protein (M1) consequently covered by a lipid bilayer from which two spiked surface glycoproteins hemagglutinin (HA) and neuraminidase (NA) arise. The glycoprotein HA is a tetramer whereas NA is a trimeric molecule [16].

IAV contains 8 RNA segments coding 7 structural proteins (PB1, PB2, PA, HA, NA, NP, and M1) and 3 nonstructural proteins (NS1, NS2, and M2) [17]. The structural proteins HA and NA are the antigenic determinants [18] and the main targets for antiviral drugs [17]. Based on these proteins, influenza A is classified into different subtypes hemagglutinin $(\mathrm{H} 1-\mathrm{H} 18)$ and neuraminidase (N1-N11).

IBV contains 8 RNA genome segments where the nonstructural protein M2 is replaced by BM2. Influenza B has 2 lineages $\mathrm{B} /$ Yamagata and $\mathrm{B} /$ Victoria and they are not classified into subtypes [19].

ICV has 7 genome segments with a single trimeric glycoprotein called hemagglutinin esterase fusion [HEF] which equalize the function of HA and NA protein [20] along with a minor envelope protein CM2 [21]. Currently, the influenza $C$ virus has 6 lineages [22].

IDV is a newly emerging virus with 7 genome segments with a matrix protein DM1 and ion channel protein DM2 [23] in association with glycoprotein hemagglutinin esterase fusion (HEF) like influenza C virus. At present, it has 2 distinct co-circulating lineages [24]. Figure 1 displays the structural description of influenza viruses.

\section{Antigenic variation}

Influenza viruses profoundly alter their surface glycoprotein resulting in an antigenic variation $[25,26]$ which exhibits in two forms antigenic drift and antigenic shift [26]. Antigenic drift is a small, gradual change of the surface antigen due to genomic point mutations [27] forming new strains of the virus, cause epidemics [28]. Random occurrence of antigenic drift is observed in influenza A, B [24], and C viruses [29]. In contrast, drastic antigenic change has not been recorded for the IDV [23]. Hence, its epidemic nature also remains undetermined. Antigenic shift occurs when a sudden extreme and profound change in genome reassortment results in the formation of a new subtype [28]. It is observed only in influenza A virus which leads to the pandemic condition [30].

\section{Vaccination remains challenge}

Vaccines are substances that provide immunity and protection against a particular infectious disease. Introducing vaccines into the body refers to vaccination and getting immunity through vaccination is immunization [31]. Every year, 3 million deaths are prevented by vaccines, and through vaccinations, the human life span has increased [32]. This shows the promising notice that vaccinations are the best way of preventing the serious effect of the dangerous disease.

Influenza is often called flu and flu vaccination is a principal tool for the prevention of influenza severity. Influenza A viruses cause pandemics whereas influenza $A$ and $B$ viruses cause seasonal epidemics. The World Health Organization [WHO] assisted with the National Influenza Centers [NIC] and Centers for Disease Control and Prevention (CDC) makes the recommendation for two different vaccine formulations every year, one for the Northern and one for the Southern Hemisphere [33].

In general, influenza vaccines are prepared in two forms as inactivated influenza vaccines (IIV) and live attenuated influenza vaccines (LAIV) [34]. Intramuscular injection of the flu vaccine is referred to as a flu shot which may be in trivalent inactivated (TIV) or quadrivalent inactivated form (QIV). The TIV is comprised of two influenza A strains and one influenza B lineage while QIV includes two influenza A strains and two influenza B lineages [35]. Figure 2 displays influenza vaccine types and drug brand names recommended by the CDC.

TIV is a standard vaccine recorded as safe and creates immunogenicity among children of 6 through 35 months of age and elderly of 65 and above [36, 37]. QIV under the brand names of AFLURIA Quadrivalent, 


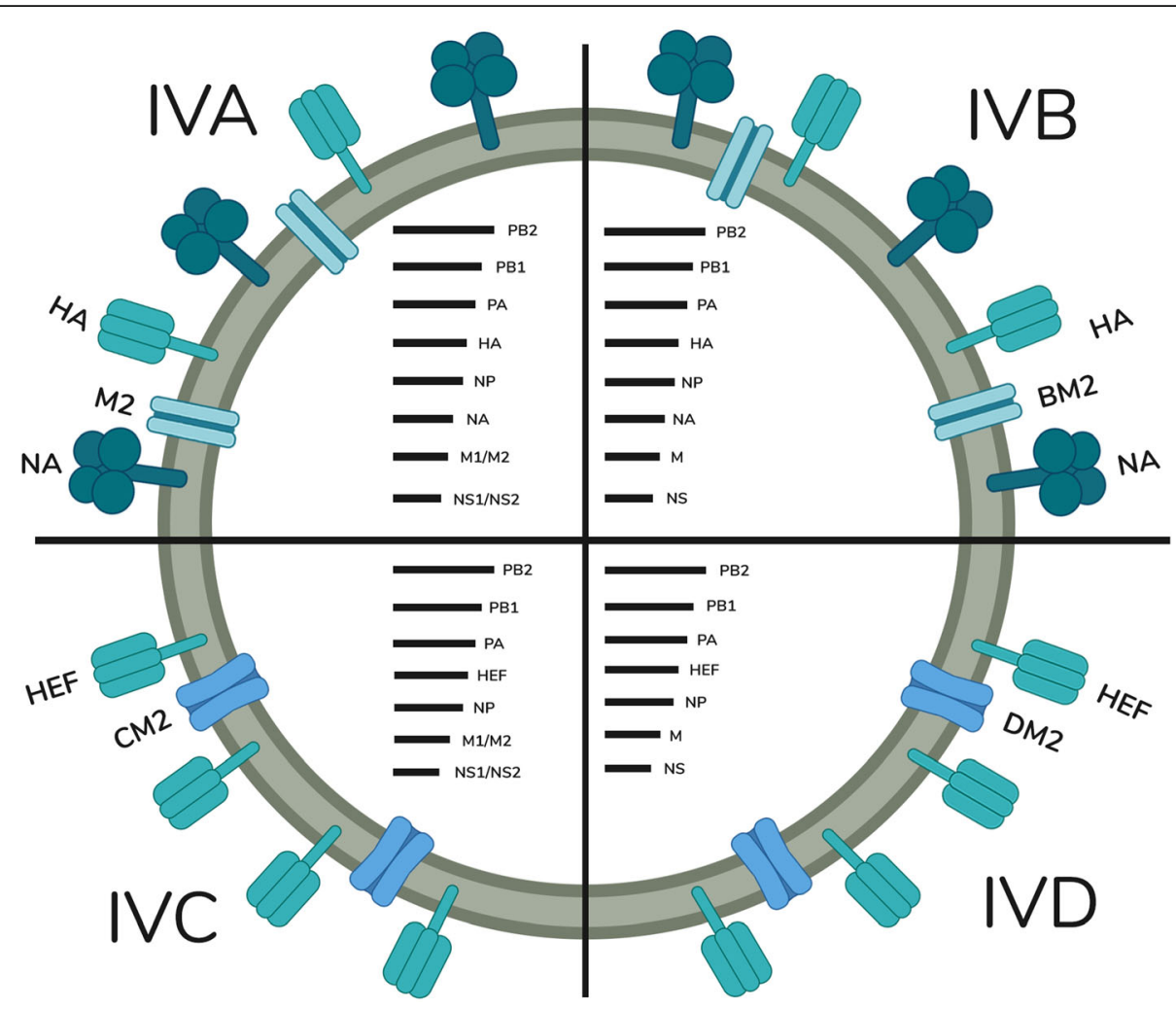

Fig. 1 Structure of influenza viruses A, B, C, and D with their genomic arrangements




Fluarix Quadrivalent, and FluLaval Quadrivalent consists of embryonated egg-grown medium vaccines, recommended for children of 6 months to 3 years, and older. People with egg allergy adapt egg-free quadrivalent vaccines like quadrivalent recombinant vaccine and quadrivalent cell-based vaccine. Quadrivalent recombinant vaccines are produced by recombinant technology where the vaccines obtained from mammalian cell culture produce quadrivalent cell-based vaccine [38]. Recently, the U.S. Food and Drug Administration (FDA) approved Flublok Quadrivalent recombinant vaccine and Flucelvax Quadrivalent cell-based vaccine for use in adults 18 years and older [39].

The High-Dose Quadrivalent vaccine with the brand name Fluzone contains four times the antigen intended to give protection for elderly people [40]. A recent study reveals that the high-dose vaccine increases the immune response [41]. AFLURIA Quadrivalent ${ }^{\circ}$ is the only vaccine approved for use with a jet injector that comes in multi-dose vials recommend for 18- to 64-year-old people [42].

Adjuvants are the compounds that enhance immunity. Currently, adjuvants like Alum, MF59 (oil-in-water emulsion), AS03 (oil-in-water adjuvant), AF03 (oil-inwater adjuvant containing squalene, montane 80 , and eumulgin b1 ph), virosomes (phospholipids), and heatlabile enterotoxin (LT) [43] are used in TIV and QIV as FLUAD and FLUAD Quadrivalent.

The Nasal Spray Flu Vaccine under the brand name of FluMist Quadrivalent is a live attenuated influenza vaccine [LAIV] is recommended by FDA in 2012 for people ages 2 to 49 . Even though the nasal vaccine stimulates the long-standing immune response, CDC not recommends it during the 2016-2017 and 2017-2018 flu seasons. This is due to its less effectiveness than IIV during the 2009 pandemic. After obtaining positive protection data of LAIV, CDC recommends it for the 2018-2019 season [44].

Mutations make the influenza viruses change over time. Hence, the genetic materials also change and new subtypes are evolved [45] which often replace the older strain [46]. It is a fact that influenza vaccines save countless lives and prevent pandemics but annual reformulation in vaccine preparation for the new emerging strains remains a challenge for the scientist [47].

Vaccine preparation takes a long time since it relies on the official declaration of the prevailing viral strain by WHO [48]. Marketing vaccine strains do not give enough protection against novel emerging strains [49]. At present, vaccines are prepared by three production technologies: egg-based, cell culture, and recombinant methods. The majority of the vaccine production is eggbased which is time-consuming and mismatching from the available and prevailing strains [48]. To overcome this, cell culture and recombinant methods of vaccine production are recently adapted, which are still in need of appropriate infrastructure to attain the goal.

Global demand for vaccines and shortage of production are growing exponentially. This is noted from the recent survey indicating that the requirement of seasonal vaccine is 1.504 billion doses but the production capacity is decreased to 1.467 billion doses $[46,50]$. The selectivity of vaccines for elderly people is also biased since vaccine efficacy differs by age and chronic diseases [51]. Hence, these conditions make developing universal influenza vaccines a big task.

\section{Conventional drugs for the disease}

Antiviral drugs are another alternative way to control and manage seasonal and post-exposure influenza [52]. They are classified into three broad categories as M2 inhibitors, neuraminidase inhibitors, and nucleoprotein inhibitors [53]. The antiviral drugs Amantadine and Rimantadine fall under M2 inhibitors, Rapivab (Peramivir), Relenza (Zanamivir), and Tamiflu (Oseltamivir Phosphate) are the neuraminidase inhibitor drugs whereas Xovluza (baloxavir marboxil) is a Nucleoprotein-inhibitor drug.

The M2 ion channel-inhibitor drugs (Amantadine and Rimantadine) are specifically used to treat influenza A infection. Currently, CDC has not recommended these drugs since they create resistance against many strains [52].

In the present scenario, CDC recommends four FDA (Food and Drug Administration)-approved antiinfluenza drugs, namely Rapivab (Peramivir), Relenza (Zanamivir), Tamiflu (Oseltamivir Phosphate), and Xovluza (baloxavir marboxil) [54]. These drugs are effective against both influenza A and B viruses [55-57].

The Neuraminidase-inhibitor drugs showed ineffectiveness against influenza $\mathrm{C}$ infection [1]. However, Baloxavir exhibits broad-spectrum antiviral activity, including influenza $C$ and D viruses [58].

Generally, antiviral drugs are targeting the viral components that are not able to combat the genetically altered emerging strains $[59,60]$ so drug-resistant strains emerge. Recent studies show neuraminidase inhibitor drug Oseltamivir also generates resistant viruses [17] like the M2-inhibitor drugs. Excessive dosages of the antiviral drugs [61] and selection pressure due to global Oseltamivir administration [62] unlikely contribute to the emergence of drug-resisting viruses.

\section{Need for new remedy}

The drawback in vaccine preparation and conventional therapies makes scientists turn their attention to powerful herbal medicines that are in great demand in the developing world [63]. A substantial increase in the consumption of herbal medicines for chronic diseases like influenza is growing exponentially $[64,65]$. They are 
the promising alternatives reckoned for their safety, compatibility, efficacy, and minimum side effects [66]. Hence, in this review, we highlight the potent herb exhibits anti-influenza activities for the control and management of influenza.

\section{Methods}

An intense database search conduct by using the keywords like herbs used against influenza, traditional medicines for influenza, and ethno medicines for influenza. Through this, we get the relevant literature up to October 2020 from scientific databases like Google Scholar, Springer, Elsevier, Sage, Taylor \& Francis, Hindawi, Wiley, Research Gate, PubMed, Scopus, Web of Science, and Shodhganga. The required data were obtained from both research and review articles published in national and international reputed journals.

\section{Alternate therapies}

Complementary and traditional medicines have been utilized for several years in various parts of the world to reduce human diseases [67]. For all these medicines, plants are the richest source. They have the active constituent phytochemical metabolites produced by the process called metabolism. This metabolism is categorized into two types as primary and secondary. Table 1 is a list of various herbs with phytochemical constituents with anti-influenza activity.

\section{Primary metabolism}

Primary metabolism is the group of all metabolic pathways synthesizing essential compounds for plant survival. Primary metabolites perform physiological functions, and these include nucleic acids, amino acids, proteins, carbohydrates, lipids, alcohol, and other natural products [152] like ester and shikimic acid.

i. Amino acid: The amino acid glutamine is essential for the synthesis of proteins and plays a critical role in the immune system. Theanine is one of the derivatives of glutamine that enhances gammadelta $\mathrm{T}$ cell function in influenza infection. Matsumoto et al. conducted a randomized, double-blind, placebo-controlled trial among 197 healthcare workers to evaluate the efficacy of Camellia sinensis Theanine and Catechin. The author divided the participants into two groups. The first group of 98 members receives catechin $(378 \mathrm{mg}$ ) and theanine $(210 \mathrm{mg})$ daily whereas the second group of 99 members act as the control group receives placebos. The main source of outcome is the incidence of clinically defined influenza infection, laboratoryconfirmed influenza with viral antigen, and the time patient is free from clinically defined infection.
From this study, the authors observed 4 participants in the first group and 13 from the control group report clinically defined influenza infection, whereas the laboratory-confirmed infection prevails in 1 member of the first group and 5 from the control group and they are statistically insignificant. From this, they concluded Theanine and Catechin might be an effective prophylaxis against influenza infection [81].

ii. Proteins: Lectins are the carbohydrate-binding protein noted in plants like Pandanus amaryllifolius [110, 117], Narcissus tazetta, and Polygonatum odoratum which exerts antiviral activity against influenza viruses [110].

Pandanin, a new antiviral lectin protein, shows its antiviral activity against the $\mathrm{H} 1 \mathrm{~N} 1$ virus at $\mathrm{EC}_{50}$ of $15.63 \mu \mathrm{M}$ with hemagglutinating activity [117].

Ooi VEC et al. screened 10 purified herbal compounds from 30 herbal extracts and perform antiviral potential studies. From the 10 herbal compounds, three proteins PYM2 of Pandanus amaryllifolius, NTL of Narcissus tazetta, and POL of Polygonatum odoratum exhibit antiviral infectivity against H1N1, H3N2, H5N1, and influenza $B$ viruses, observed through plaque reduction assay. AntiH5N1 efficacy of PYM2 ( $\left.\mathrm{IC}_{50} 26.03 \mu \mathrm{g} / \mathrm{mL}\right)$ and POL $\left(\mathrm{IC}_{50} 6.23 \mu \mathrm{g} / \mathrm{mL}\right)$ are further investigated by introducing $5 \mathrm{mg} / \mathrm{kg}$ of the proteins in mouse macrophages where the upregulation of cytokines IL-1 $\beta$, IL-12, IFN- $\gamma$, and TNF- $\alpha$ was observed [110].

Narcissus tazetta lectin is a mannose-binding Lectin protein. Linda S M Ooi et al. describe NTL viral inhibition activity by using an extracellular virus yield reduction assay. NTL inhibits $\mathrm{H} 1 \mathrm{~N} 1, \mathrm{H} 3 \mathrm{~N} 2$, and influenza B viruses $\quad(\mathrm{A}(\mathrm{H} 1 \mathrm{~N} 1) /$ HongKong/CUHK-13003/2002, A(H3N2)/HongKong/CUHK22910/2004, A(H5N1)/HongKong/483/1997, and B/HongKong/CUHK-24964/2004) in a dose-dependent manner $\left(\mathrm{EC}_{50}\right.$ values ranging from $0.02 \mu \mathrm{g} / \mathrm{mL}$ to $1.33 \mu \mathrm{g} / \mathrm{mL}$ ) but with moderate inhibition on H5N1. The study also shows evidence of NTL inhibiting the H1N1's early phase of replication by interacting with surface glycoproteins, thereby avoid the virus for adherence and fusion [111].

NTP is a fetuin-binding non-specific lipid transfer protein (nsLTPs) of Narcissus tazetta that blocks the neuraminidase of H1N1 (EC 50 of $4.47 \mathrm{mg} / \mathrm{mL}$ ) thereby inhibiting the replication which is revealed from a MTT assay [112].

iii. Carbohydrates: Carbohydrates are the major constituents of the plant which are produced by the photosynthetic process [153]. They are produced in larger amounts and are classified into four types as Monosaccharides, Disaccharides, Oligosaccharides, and Polysaccharides. 


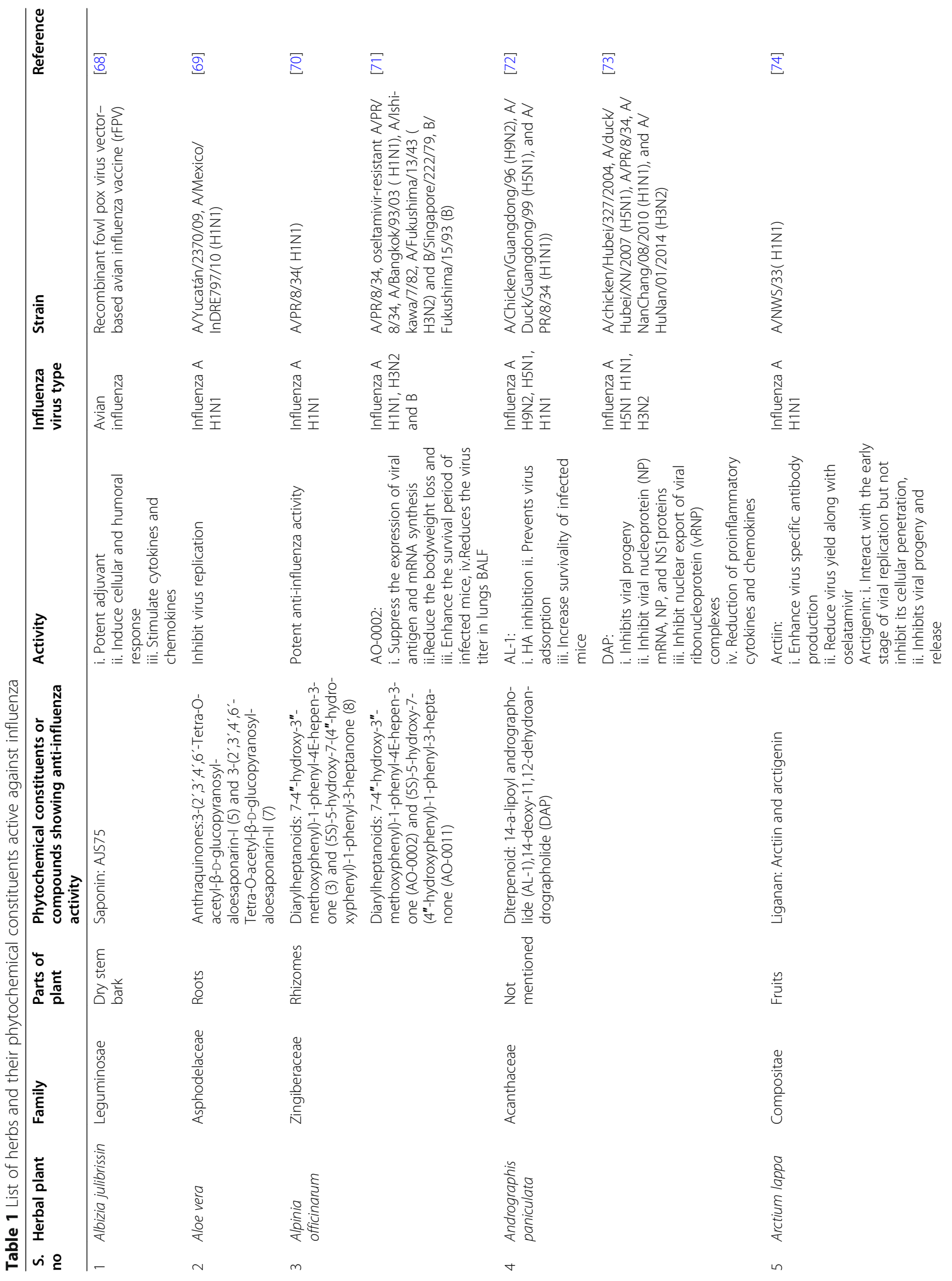




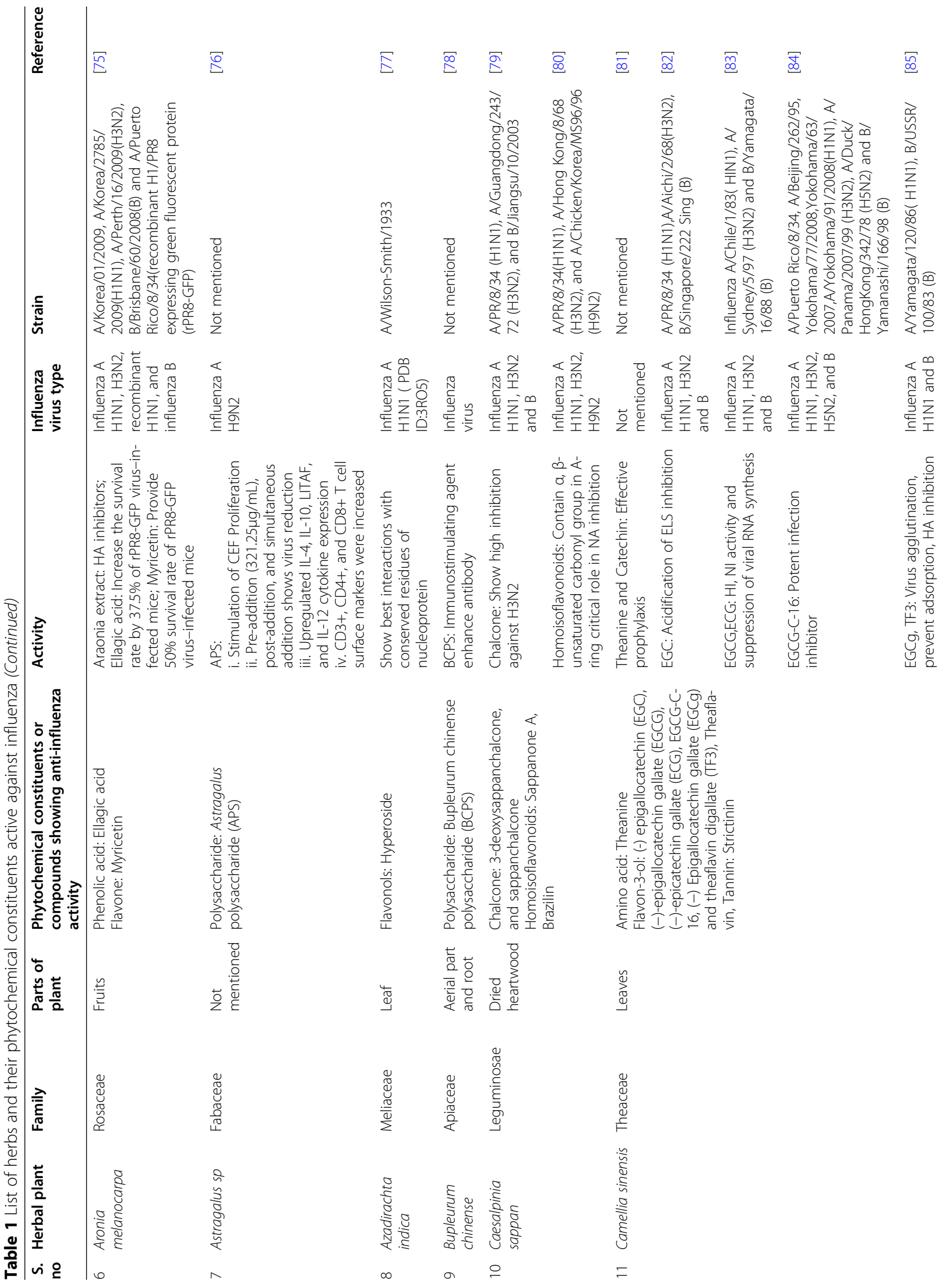




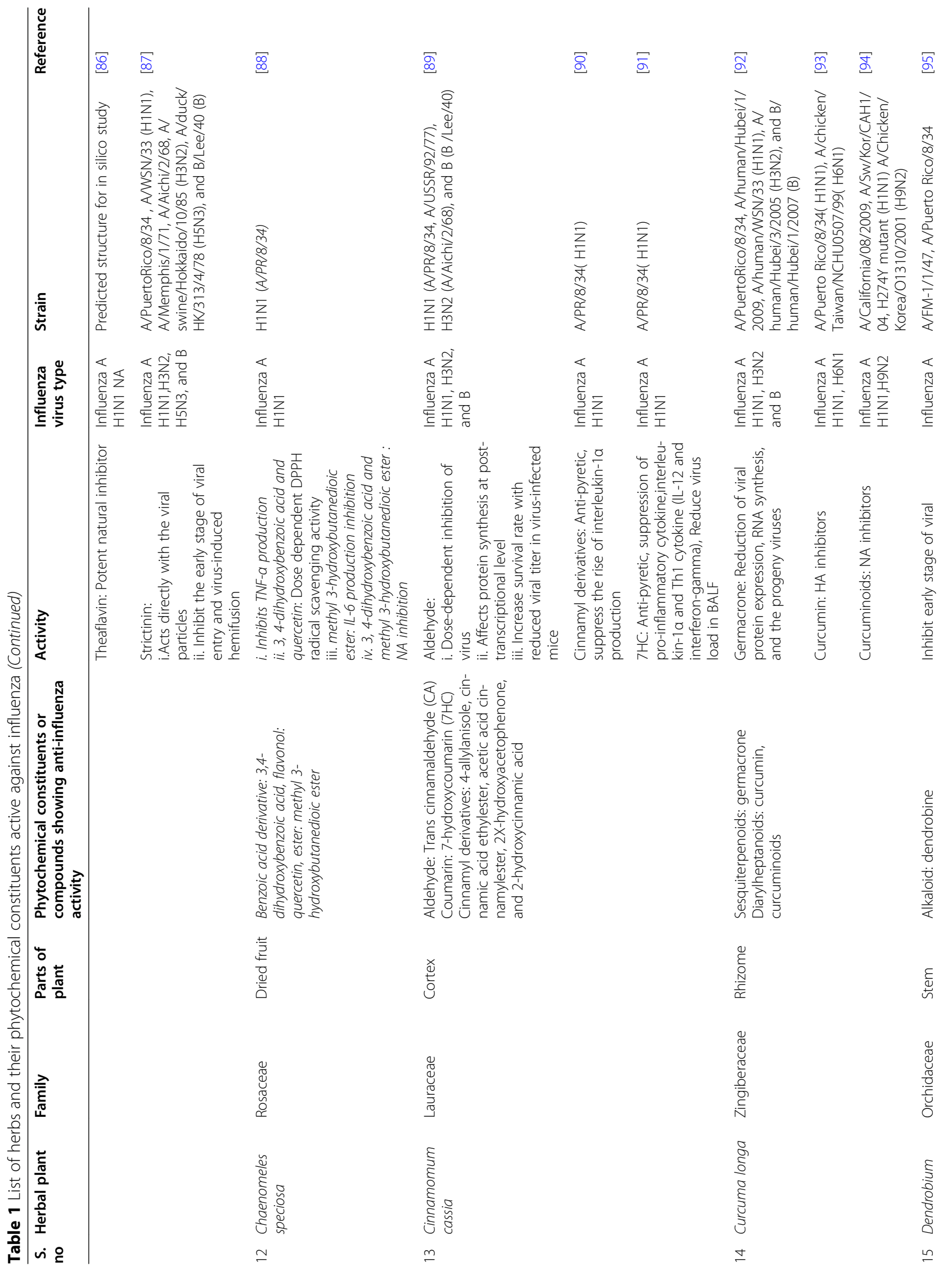




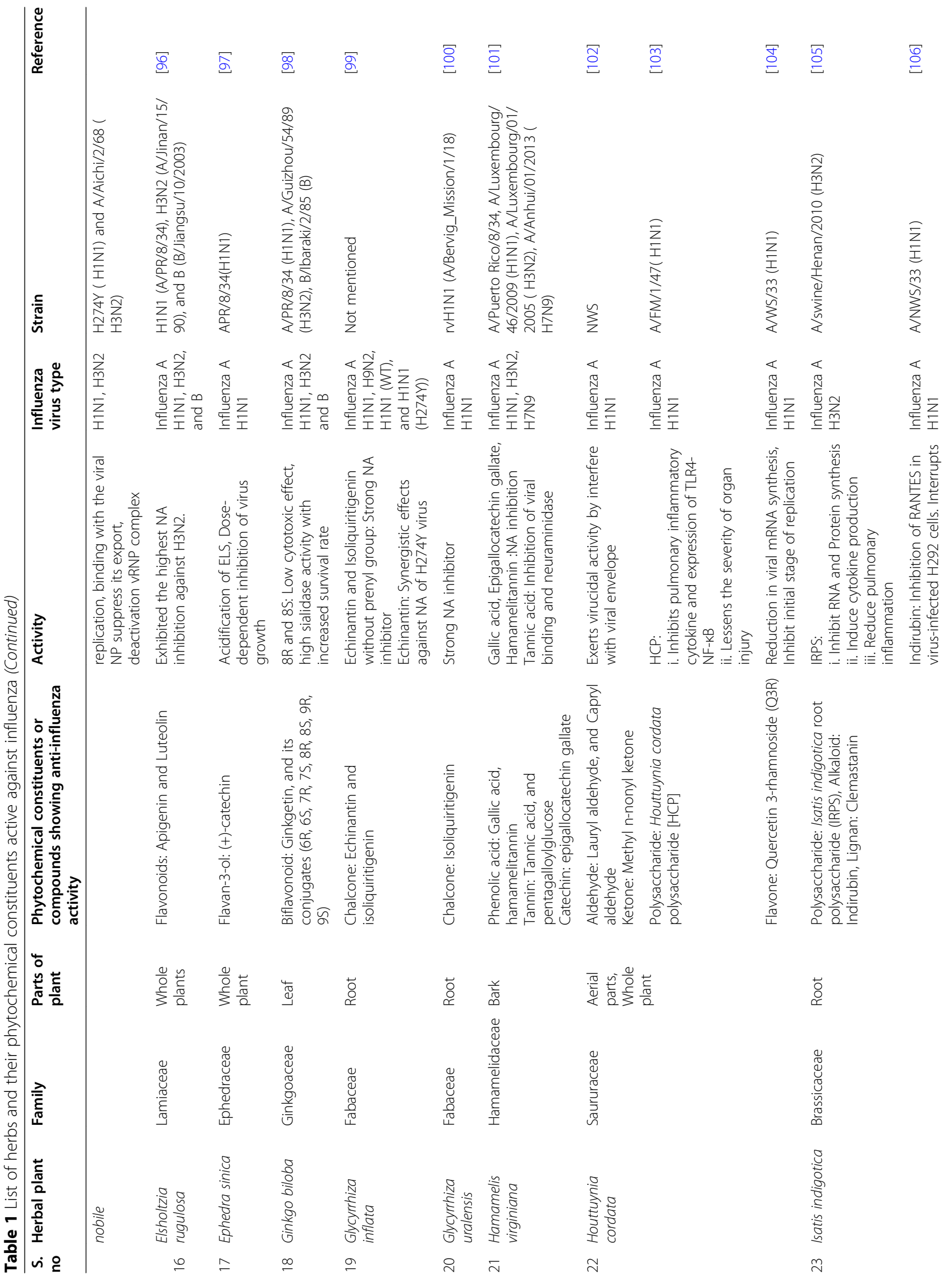




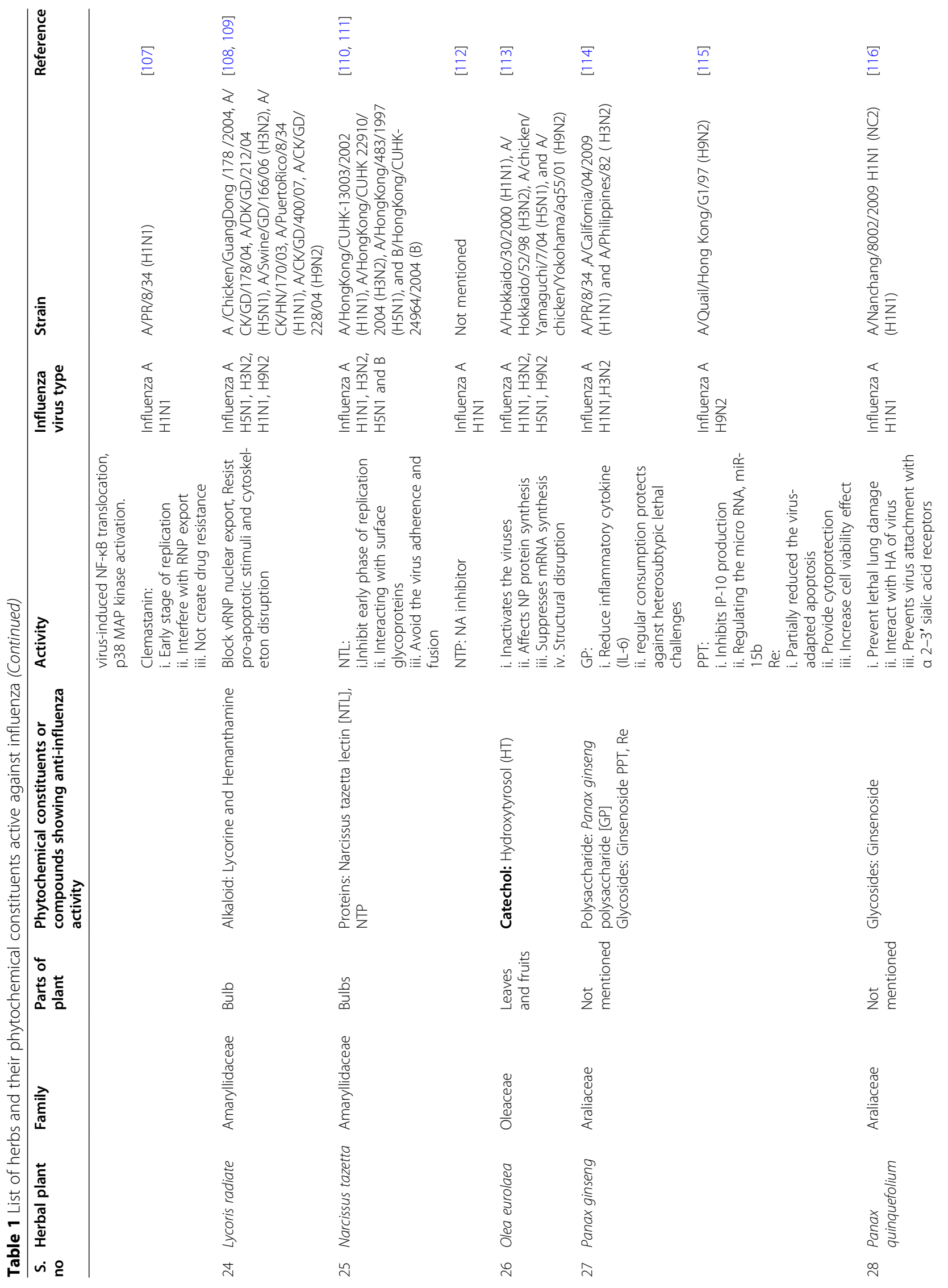




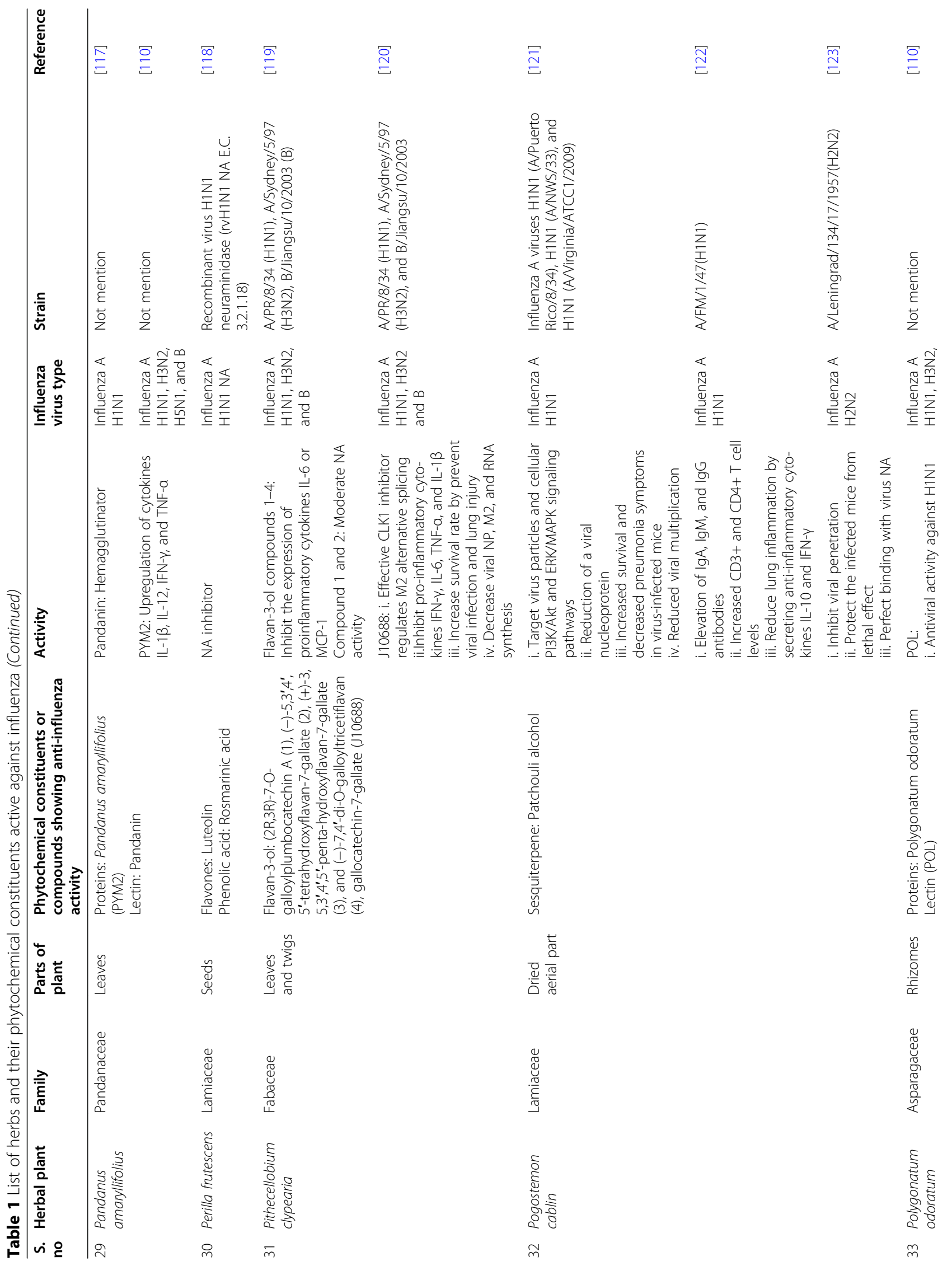




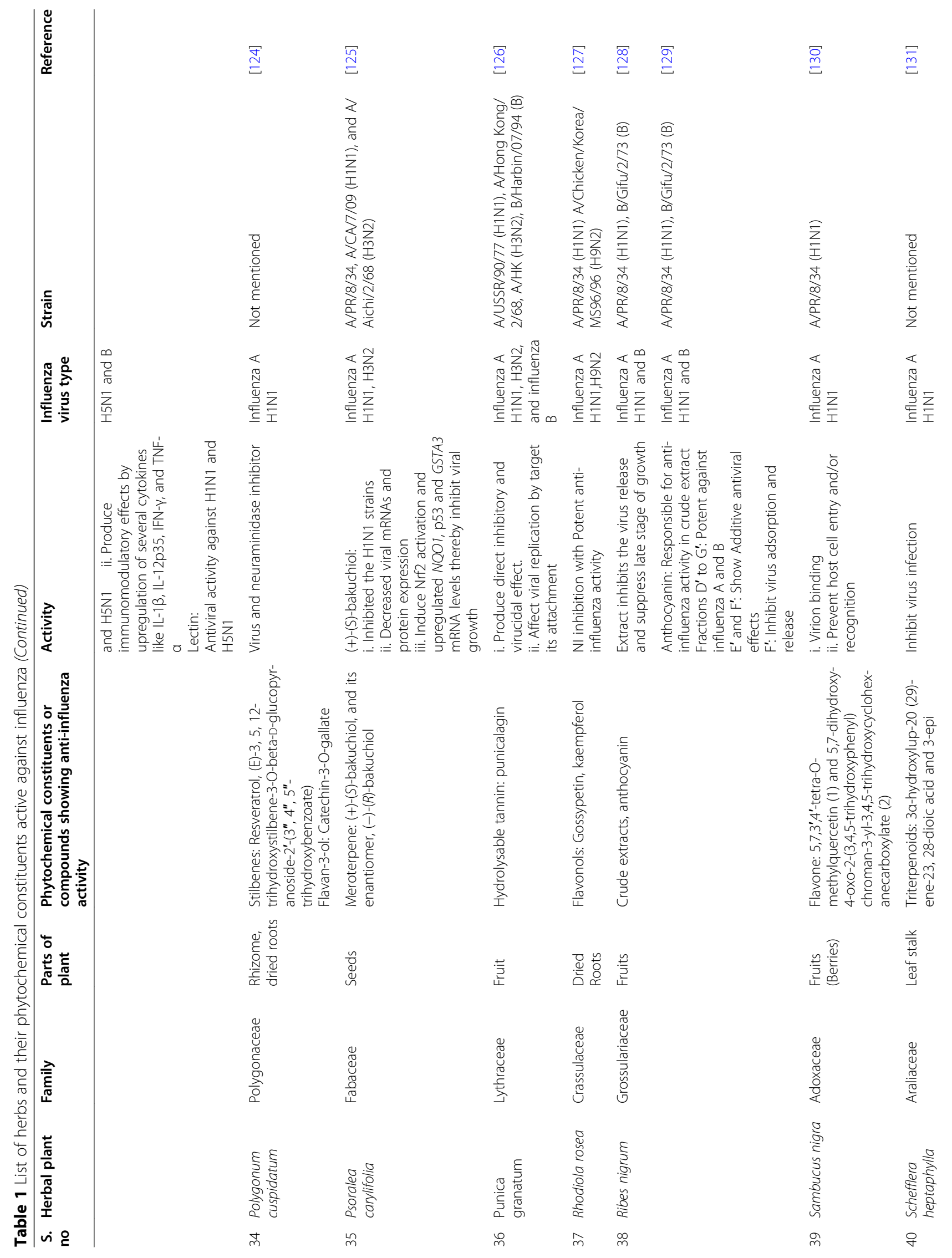









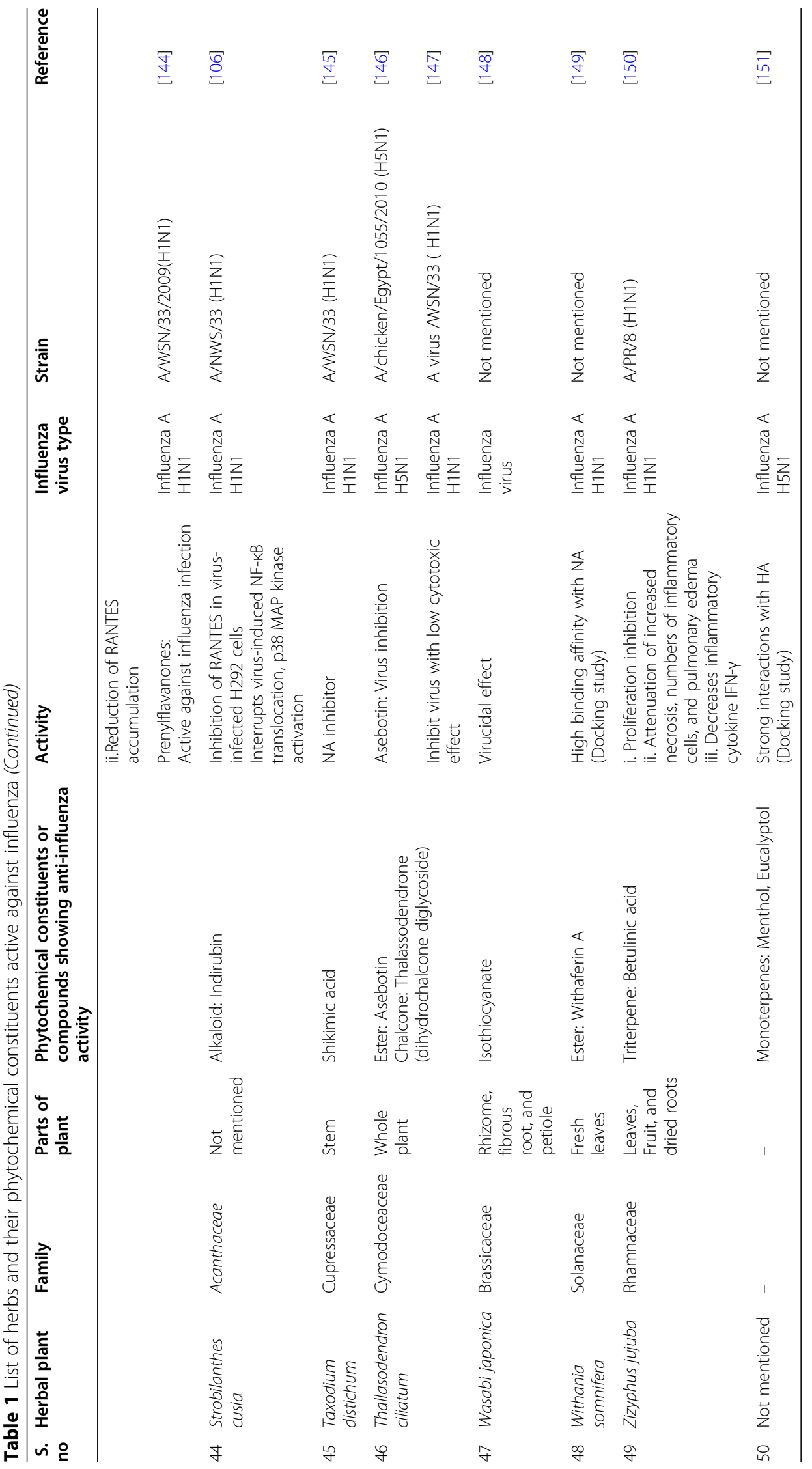


Monosaccharides are the simplest carbohydrates that have polyhydroxy aldehyde or ketone groups [154]. Hayashi et al. demonstrate direct influenza H1N1 inhibitory activity of the Houttuynia cordata steam distillate without any cytotoxic effect against HeLa and MDCK cells. Aldehyde such as lauryl aldehyde and capryl aldehyde and ketone including methyl-nonyl ketone were the components of distillate which inactivate the influenza virus. The virus inactivation assay reveals either the distillate or its components exert virucidal activity by interfering with the function of the viral envelope [102].

Hayashi et al. isolated trans cinnamaldehyde (CA) from the cortex of Cinnamomum cassia and analyze its anti-influenza efficiency against $\mathrm{H} 1 \mathrm{~N} 1 \mathrm{~A} / \mathrm{PR} / 8 / 34$, A/ USSR/92/77), H3N2 (A/Aichi/2/68), and B (B/Lee/40). The in vitro study reveals dose-dependent inhibition of CA where $40 \mu \mathrm{M}$ reduces $29.7 \%$ virus yield at $3 \mathrm{~h}$ p.i. and $200 \mu \mathrm{M}$ treatment does not show the virus growth.CA affects protein synthesis at post-transcriptional level but not degrade the preexisting or synthesized proteins. To the mouse lung-adapted PR8 virus-infected mice, CA administered through inhalation and nasal inoculation which shows $100 \%$ and $70 \%$ increasing survival rate on 8 days without remarkable weight loss. Notably, CA inhalator mouse bronchoalveolar lavage fluid (BALF) shows a decrease in virus yield by $1 \log$ [89].

Polysaccharides are complex monosaccharides that play an essential role in the pharmaceutical industry for their effective inhibitory response against viruses like Influenza, HIV, Coxsackie virus B3 [CVB3], herpes simplex virus, hepatitis virus, and cytomeglalovirus [155]. Various polysaccharides isolated from the herbs like Bupleurum chinense [BCPS], Houttuynia cordata [HCP], Isatis indigotica root [IRPS], Panax ginseng [GP], and Astragalus polysaccharide (APS) proved to be boosting up various immunological activities and prevent the effect of influenza infection.

Bupleurum chinense polysaccharides [BCPS] act as an immunostimulating agent which enhances anti-influenza virus antibody. This was well demonstrated by Zhang and Chen's studies, by injecting $100 \mathrm{mg} / \mathrm{kg}$ of BCPS in normal and influenza-infected mice. The results show increased lymphocyte transformation and enhanced NK cell function [78].

Houttuynia cordata polysaccharide [HCP] lessens the severity of organ injury due to influenza virus infection. Zhu et al. discovered its role by administered orally by gavages to H1N1 (A/FM/1/47)-infected mice and observed an increase in survival rate through inhibition of the release of pulmonary inflammatory cytokine and expression of TLR4-NF-kB. Restoring and improvement of damaged tissue also noted [103].

Isatis indigotica root polysaccharide (IRPS) show a low cytotoxic effect and promote proliferation $(1.25 \mathrm{mg} / \mathrm{mL}$ concentration) in MDCK cells infected with swine influenza virus (SIV) $\mathrm{H} 3 \mathrm{~N} 2$ of the strain (A/swine/Henan/ 2010). Through MTT assay, the preventive, inhibitory, and direct effect of IRPS against SIV was observed. IRPS $(312.5-1250 \mu \mathrm{g} / \mathrm{mL})$ increases the percentage of prevention from 12.64 to $74.00 \%$ which shows the MDCK cell protection with enhanced antiviral ability. In addition to that, the cell membrane was stabilized by IRPS, which provides the potential to inhibit adsorption, penetration, and infection of SIV. A dose-dependent increase of IRPS $(156.25-1250 \mu \mathrm{g} / \mathrm{mL})$ increased the percentage of inhibition from $31.92 \%$ to $84.95 \%$ suggested; IRPS may play a potent role in inhibiting viral RNA and protein synthesis. Surprisingly, IRPS direct effect was found to be weak in SIV-adapted MDCK cells. By in vivo study, the mice were orally administered with varying doses of IRPS chosen as $75 \mathrm{mg} / \mathrm{kg} /$ day, $50 \mathrm{mg} / \mathrm{kg} /$ day, and $25 \mathrm{mg} / \mathrm{kg} /$ day before the infection. The mice at 3 dpi show significant clinical signs, while at high dosage applied, $5 \mathrm{dpi}$ regained the weight. The IRPS reduced pathological changes, with improved lesions and normal alveolar structure. Host immunity signaling molecule NO (Nitric oxide) was increased at 2 and $5 \mathrm{dpi}$; similarly, the antibody IgG in blood serum is increased significantly at 9 dpi. IRPS induces cytokine production and reduces pulmonary inflammation, which was evident from the detection of cytokine in lung homogenate [105].

Panax ginseng polysaccharide [GP] increases the survival rate of $\mathrm{H} 1 \mathrm{~N} 1 \quad(\mathrm{~A} / \mathrm{PR} / 8 / 34)$-, (A/California/04/ 2009)-, and H3N2 (A/Philippines/82)-infected mice by providing intranasal $25 \mathrm{mg} / \mathrm{kg}$ or intravenous $10 \mathrm{mg} / \mathrm{kg}$ doses. The GP-treated H1N1 infect mice exhibit a lower level of viral titer along with reduced inflammatory cytokine (IL-6). It is noted that a higher dosage does not increase the survival rate. GP provides protection effect even before the influenza infection, and regular consumption protects against heterosubtypic lethal challenges [114].

In this study, Kallon et al. use Astragalus polysaccharide (APS) against H9N2-infected chick embryo fibroblasts (CEF) culture. APS of $321.25 \mu \mathrm{g} / \mathrm{mL}$ concentrations is determined as optimal for the stimulation of CEF Proliferation. Appropriate dosage of APS administered during pre-addition $(321.25 \mu \mathrm{g} / \mathrm{mL})$, postaddition, and simultaneous addition shows a significant reduction of viruses. APS upregulated IL-4, IL-10, LITA F, and IL-12 cytokine expression but IFN- $\gamma$, LITAF, IL6 , and IL-12 were downregulated. APS inoculation decreased MHC I and MHC II expression but increased after H9N2 infection. Peripheral blood lymphocytes expressing $\mathrm{CD} 3+, \mathrm{CD} 4+$, and $\mathrm{CD} 8+\mathrm{T}$ cell surface markers were increased after APS immunization. Postimmunization of APS $(5 \mathrm{mg} / \mathrm{kg})$ enhanced the antibody titer at 7 and 14 days [76]. 
iv. Ester: Ester has ideal characteristics with chemical stability. Its unique characters attract to create prodrug [156]. Several ester compounds show promising anti-influenza features.

Zhang et al. isolated 13 compounds from the dried fruit powders of Chaenomeles speciosa and identify 3, 4dihydroxybenzoic acid (Benzoic acid derivative), quercetin (flavonol), and methyl 3-hydroxybutanedioic ester (Ester) showed remarkable anti-influenza activity. The compounds 3, 4-dihydroxybenzoic acid ( $\mathrm{IC}_{50} 1.02 \mu \mathrm{g} /$ $\mathrm{mL}$ ), and quercetin $\left(\mathrm{IC}_{50} 3.82 \mu \mathrm{g} / \mathrm{mL}\right)$ displayed significant dose-dependent DPPH radical scavenging activity. $5 \mu \mathrm{g} / \mathrm{mL}$ of 3, 4-dihydroxybenzoic acid, quercetin, and methyl 3-hydroxybutanedioic ester inhibit TNF- $\alpha$ by $22.73 \%, 33.14 \%$, and $37.19 \%$ and NO production inhibition. High IL-6 production inhibition (39.79\%) was observed in methyl 3-hydroxybutanedioic ester. The compounds 3, 4-dihydroxybenzoic acid ( $\mathrm{IC}_{50} 1.27 \mu \mathrm{g} /$ $\mathrm{mL}$ ) and methyl 3-hydroxybutanedioic ester $\left(\mathrm{IC}_{50} 1.90\right.$ $\mu \mathrm{g} / \mathrm{mL}$ ) featured H1N1 (A/PR/8/34) NA inhibition activity $i$ a dose-dependent manner [88].

The study of Ibrahim et al. informed that a new diglyceride ester along with asebotin (a dihydrochalcone) from Thallasodendron ciliatum exerted anti-AIV activity against A/chicken/Egypt/1055/2010 (H5N1) in MDCK cells. This compound inhibited the virus with a concentration of $1 \mathrm{ng} \mathrm{mL} \mathrm{m}^{-1}$ by a percentage of 67.26 and 53.81 . Its efficacy was similar to zanamivir which showed a higher concentration of inhibition of $10 \mathrm{ng} \mathrm{mL}^{-} 1$ [146].

Cai et al. validated Withaferin A of Withania somnifera as a potent source for H1N1 NA inhibition through docking studies. In the study, Withaferin A shows a high binding affinity towards NA [149].

xxiiShikimic acid: Shikimic acid is an important biochemical metabolite and its pathway is essential for the synthesis of plant amino acid [157]. Antiviral drug Tamiflu is prepared by using shikimic acid as base material [158]. Several plants and their parts like fruits of Illicium religiosum and Illicium verum, barks of Illicium anisatum, Pinus thunbergii, and Pinus densiflora, stems and leaves of Saxifraga stolonifera, and Houttuynia cordata exhibits high shikimic acid content [159].

Recently shikimic acid has been noted in Taxodium distichum extract and it is a carbocyclic sialic acid analog. Hence, the authors Hsieh et al. [145] suggest that it may also exert the function as a neuraminidase inhibitor.

\section{Secondary metabolism}

Secondary metabolism comprises metabolic pathways which are not essential for the functioning or survival of the plant. Both primary and secondary metabolism, along with their regulatory pathways facilitates the plant to survive under stressful conditions [160]. Interestingly the secondary metabolites are derived from the primary metabolites and their various pathways [161]. Indeed, plants produce a wide array of secondary metabolites, but there is no precontrived and commonly agreed system of classification [162]. However, based on their chemical structure and biosynthetic origin, they are classified into three major classes as terpenes, alkaloids, and phenolics [163]. In addition to this, some special categories like terpenoids, glycosides, diaryl heptanoids, and isothiocyanates are included under secondary metabolites. Figure 3 categorizes the various classes of secondary metabolites.

\section{Terpenes}

Terpenes are a large class of secondary metabolites and they are classified based on the isoprene unit. monoterpenes, sesquiterpene, triterpene, and meroterpene are the various classes of terpenes $[164,165]$.

\section{Monoterpenes}

Gangopadhyay et al. used Hex 5.1 Docking software and dock 13 herbal and lead inhibitors with wild-type and mutant haemagglutinins of H5N1. The study reveals that the monoterpenes menthol and eucalyptol show strong interactions by binding to glutamate 11 site of haemagglutinin thereby inhibiting viral fusion with the host cell [151].

\section{Sesquiterpene}

Patchouli alcohol (PA) is a sesquiterpene extracted from Pogostemon cablin. Yu et al. investigated both in vitro and in vivo anti-influenza activity of PA against H1N1 (A/Puerto Rico/8/34, A/NWS/33, and A/Virginia/ ATCC1/2009). The in vitro time-of-addition assay (TOA) indicates the reduction of viral multiplication is observed before and after infection. The anti-viral mechanisms of action were studied, by using neuraminidase inhibition assay (NI), hemagglutination inhibition (HI) assay, and western blot assay. This study explores PA neither inhibits NA nor HA of the influenza viruses, but it targets virus particles and cellular PI3K/Akt and ERK/ MAPK signaling pathways thereby arresting the viral infection. Reduction of a viral nucleoprotein by PA was noticed by western blot assay. The in vivo study is carried by intranasal administration of PA to the IAVinfected mouse pneumonia model. This study explores the increased survival, decreased pneumonia symptoms comparable to the effects of Oseltamivir [121].

$\mathrm{Li}$ et al. perform in vivo anti-influenza studies by oral administration of Patchouli alcohol (PA) $(20 \mathrm{mg} / \mathrm{kg}$ to $80 \mathrm{mg} / \mathrm{kg}$ ) into the influenza A virus (A/FM/1/47)- 


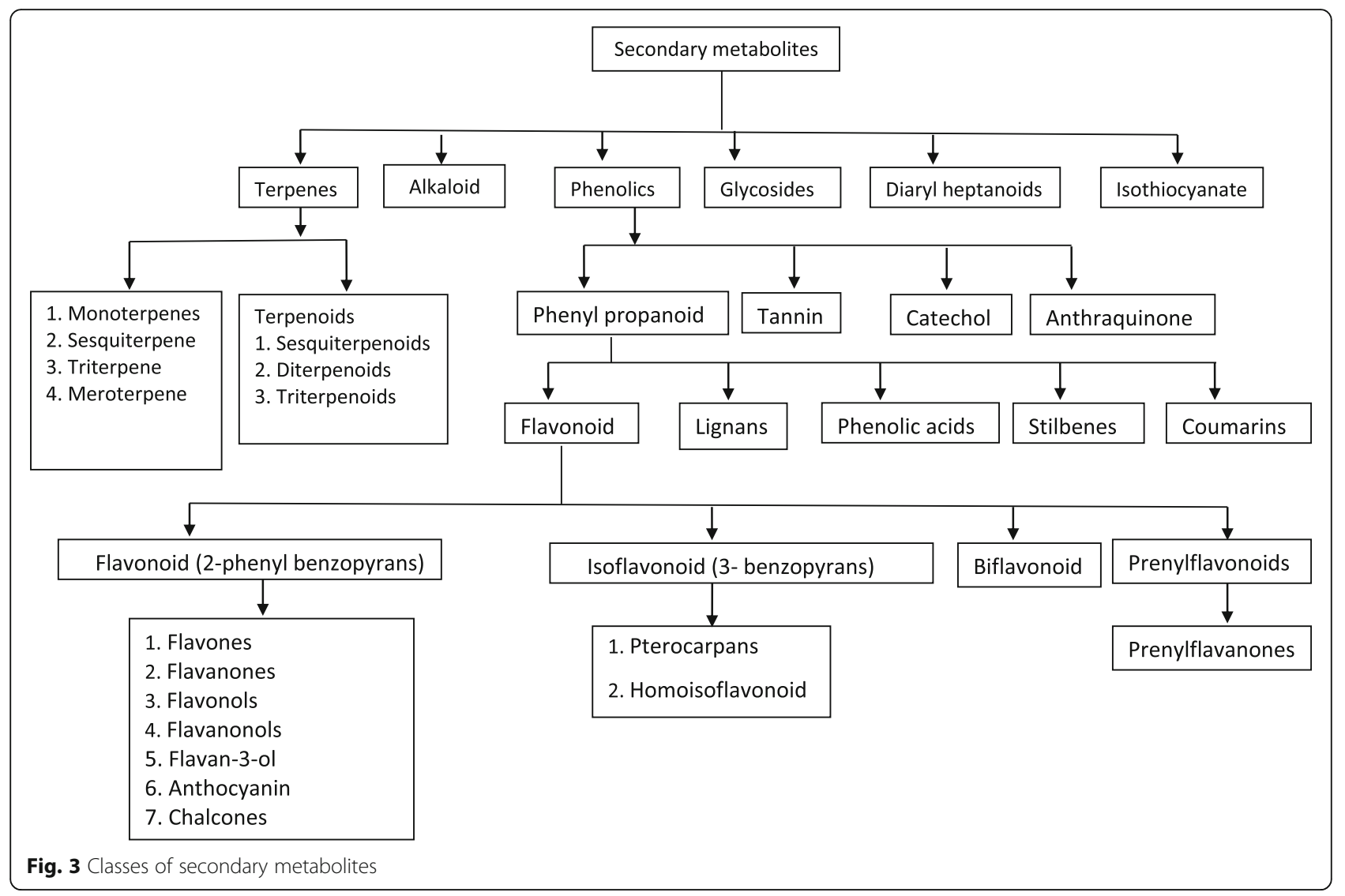

infected mice. This study noticed the improved survival rate of the infected mice. The humoral immune response is detected by using an enzyme-linked immunosorbent assay (ELISA) which detects the elevation of IgA, IgM, and IgG antibodies. The flow cytometric analysis is used to detect cell-mediated immune response which results in the increased $\mathrm{CD} 3+$ and $\mathrm{CD} 4+\mathrm{T}$ cell levels. An increase in the production of antiinflammatory cytokines IL-10 and IFN- $\gamma$ reveals the reduction of lung inflammation due to infection [122].

$\mathrm{Wu}$ et al. [123] investigate in vitro, in vivo, and in silico studies on Patchouli alcohol (PA) against influenza A virus (A/Leningrad/134/17/1957, H2N2). In vivo, MTT assay reveals PA at IC50 of $4.03 \pm 0.23 \mu \mathrm{M}$ inhibits the viral penetration. Through in vivo, PA at a dose of $5 \mathrm{mg} / \mathrm{kg} /$ day protects the infected mice, comparable with Oseltamivir. In silico docking and molecular dynamic simulations exhibit PA binding in the Asp151, Arg152, Glu119, Glu276, and Tyr406 active site regions of H2N2 NA with interaction energy of $-40.38 \mathrm{kcal}$ $\mathrm{mol}^{-1}$.

\section{Triterpene}

The study of Hong et al. investigates triterpene compounds, Betulinic acid (BeA), of Zizyphus jujuba have antiviral activity against influenza A/PR/8-infected A549 cell line and C57BL/6 mice. In in vivo study, the SRB method assesses proliferation inhibition in a dosedependent manner $(0.4-50 \mu \mathrm{M})$ in A549 cells without major cytotoxicity. Intraperitoneally administering BeA $(10 \mathrm{mg} / \mathrm{kg} / \mathrm{dose}$ ) into the infected mice reveals the attenuation of increased necrosis, inflammatory cells, and pulmonary edema. ELISA study marks the decreased level of inflammatory cytokine IFN- $\gamma$ level in BeAtreated infected mouse lung [150].

\section{Meroterpene}

Bakuchiol is a meroterpene compound derived from Psoralea carylifolia. Shoji et al. investigate naturally occurring (+)-(S)-bakuchiol and synthetic enantiomer (-)-(R)-bakuchiol against influenza A viral strains A/ $\mathrm{PR} / 8 / 34, \mathrm{~A} / \mathrm{CA} / 7 / 09$ (H1N1), and A/Aichi/2/68 (H3N2) and observed (+)-(S)-bakuchiol inhibited the H1N1 strains but not the H3N2 strain by inhibiting viral growth, decreased viral mRNAs and protein expression in MDCK cells. Naturally occurring (+)-(S)bakuchiol shows greater anti-influenza activity than enantiomer (-)-(R)-bakuchiol. Bakuchiol induced Nrf2 activation and upregulated NQO1, p53, and GSTA3 mRNA levels in MDCK cells thereby inhibiting viral growth [125]. 


\section{Terpenoids}

Terpenoids are a modified class of terpenes with various cyclizations and rearrangement of the carbon skeleton $[165,166]$. Sesquiterpenoids, diterpenoids, and triterpenoids are the various types of terpenoids. Terpenoidderived drugs gained significant attention towards the treatment of human infectious diseases [167].

\section{Sesquiterpenoids}

Sesquiterpenoids are derived from sesquiterpenes showing diverse hydrocarbon backbone [168].

The Sesquiterpenoid Germacrone is one of the active components found in the rhizome of Curcuma longa. Liao et al. explain the antiviral activity of Germacrone against influenza A viruses (A/PuertoRico/8/34, A/human/Hubei/1/2009, A/human/WSN/33 (H1N1), A/human/Hubei/3/2005 (H3N2), and influenza B viruses (B/ human/Hubei/1/2007) in MDCK and A549 cells by the dose-dependent manner with $\mathrm{EC}_{50}$ of $6.03 \mu \mathrm{M}$. The neuraminidase assay in A549 cells and plaque reduction assay show reduced NA and plaque numbers. Through indirect immunofluorescence assay, reduction of viral protein expression, RNA synthesis, and the progeny viruses observed both in MDCK and A549 cells. In a time-of-addition study, the early stage of viral inhibitory activities was observed. Germacrone administered at 100 $\mathrm{mg} / \mathrm{kg}$ provides effective protection. Moreover, the studies suggested Germacrone in combination with oseltamivir produces a significant effect [92].

\section{Diterpenoid}

Diterpenoid compounds belong to the Terpenoid class [169] that is produced by diterpene synthases (diTPSs) and other enzymes resulting in a wide structural diversity [170]. Generally, these compounds are odorless with strong flavors.

Andrographolide is a Diterpenoid obtained from Andrographis paniculata. Recent studies show Andrographolide derivatives have potent activity opposing influenza infection. 14-a-lipoyl andrographolide (AL-1) is the synthesized Andrographolide derivative studied by Chen et al. against influenza A viruses (A/Chicken/ Guangdong/96 (H9N2), A/Duck/Guangdong/99 (H5N1), and $\mathrm{A} / \mathrm{PR} / 8 / 34(\mathrm{H} 1 \mathrm{~N} 1)$ ) in MDCK cells. The in vivo plaque reduction assay using $\mathrm{EC}_{50}$ of 7.2 to $15.2 \mathrm{mM}$ exhibited the most effective antiviral activities in MDCK cells. Hemagglutination assays show a minimum inhibitory concentration range of $5.3-16.8 \mathrm{mM}$ indicate that AL-1 directly inhibits hemagglutinin and prevents virus adsorption. In vivo render positive information like prolonged survival, decreased lung consolidation of infected mice by oral gavages of AL-1 ranged from 100 to 200 $\mathrm{mg} / \mathrm{kg} /$ days. The best result was obtained by administered twice daily for 7 days beginning $24 \mathrm{~h}$ before viral exposure [72].

Another Andrographolide derivatives compound, 14deoxy-11,12-dehydroandrographolide (DAP), has potency against influenza A viruses (A/chicken/Hubei/327/ 2004, A/duck/Hubei/XN/2007 (H5N1), A/PR/8/34, A/ NanChang/08/2010 (H1N1), and A/HuNan/01/2014 (H3N2)) in vitro, with $\mathrm{CC}_{50}$ values of 77 and $243 \mathrm{lg} / \mathrm{mL}$ in both A549 and MDCK cells. CCK-8 assay detects DAP exerts no cytotoxic effect on the cells and the morphology of the cells remains unaffected. But it shows a pronounced inhibitory effect on viral progeny. Further analysis of DAP is continued with $\mathrm{H} 5 \mathrm{~N} 1$ virus (A/ chicken/Hubei/327/2004) where viral nucleoprotein (NP) mRNA, NP, and NS1proteins were significantly inhibited but it does not show any effect on the absorption from A549 cells. Immunostaining assay explores Dap effective control in inhibiting nuclear export of viral ribonucleoprotein (vRNP) complexes. The qRT-PCR reduction of proinflammatory cytokines (TNF-a, IL-6, IL8, IFN-a, IL-1b, and IFN-b) and chemokines (CXCL-10 and CCL-2) by DAP was observed [73].

\section{Triterpenoids}

Triterpenoids are the oxygen derivatives of triterpenes [171]. Triterpenoids 3 $\alpha$-hydroxylup-20(29)-ene-23,28dioic acid and 3-epi-betulinic acid 3-O-sulfate isolated from Schefflera heptaphylla profoundly active against influenza A (H1N1) virus with $\mathrm{IC}_{50}$ values of 25 and 31.3 $\mu \mathrm{g} / \mathrm{mL}[131]$.

\section{Alkaloids}

Alkaloids are nitrogen-containing secondary metabolites. Most of the alkaloids are pharmacologically active compounds [172]. Some of the noted alkaloids like dendrobine of Dendrobium nobile, Indirubin of Isatis indigotica and Strobilanthes cusia, Lycorine and Hemanthamine of Lycoris radiate, Quinalizidine alkaloids of Sophora species, ormosinine appraise for their efficacy against influenza viruses.

The plant Dendrobium nobile stem is enriched with alkaloids namely Dendrobine. Li et al. expose dendrobine anti-influenza activity against H1N1 (A/FM-1/1/47, A/ Puerto Rico/8/34 H274Y) and H3N2 (A/Aichi/2/68) with $\mathrm{IC}_{50}$ values of $3.39 \pm 0.32,2.16 \pm 0.91,5.32 \pm 1.68$ $\mu \mathrm{g} / \mathrm{mL}$, respectively. dendrobine inhibited the production of viral HA mRNA, HA, and NP proteins in both MDCK and A549 cells in a dose-dependent manner. It inhibited the early stage of viral replication by binding with the viral NP (Affinity constant $\mathrm{K}_{\mathrm{D}}$ value: $1.19 \times 10$ $-2 \mu \mathrm{g} / \mathrm{mL}$ ) thereby suppress its export resulting in the deactivation of the vRNP complex. In support of these findings, a docking study performed using AutoDock 
software revealed the binding of dendrobine in the highly conserved region of viral NP [95].

Herbs like Isatis indigotica and Strobilanthes cusia are enriched with Indirubin pigment used to treat respiratory viral infection. Mak et al. displayed the antiinfluenza virus activity by inhibition of RANTES in influenza A (A/NWS/33)-infected H292 cells. It interrupts virus-induced NF- $\mathrm{kB}$ translocation and p38 MAP kinase activation [106].

Lycoris radiate bulbs have been used as traditional Chinese medicine. He et al. isolated and identified 15 alkaloids from it using spectroscopic analysis. Among these, four alkaloids lycorine, hippeastrine, hemanthamine, and 11-hydroxyvittatine exhibited antiviral activities against H5N1 (A/Chicken/Guangdong/178/2004) in MDCK cells with $\mathrm{EC}_{90}$ values of $0.52,82.07,4.15$, and $13.45 \mu \mathrm{m}$. From these Lycorine and Hemanthamine were further analyzed which block vRNP nuclear export [108].

In another study, Lycorine and Hemanthamine were further investigated by $\mathrm{He}$ et al. These compounds exert antiviral activity against H5N1 (A/CK/GD/178/04, A/ DK/GD/212/04), H3N2 (A/Swine/GD/166/06), H1N1 (A/CK/HN/170/03, A/PuertoRico/8/34), H9N2 (A/CK/ GD/400/07, A/CK/GD/228/04) in MDCK cells after the viral entry. These drugs display cytostatic effects by resisting pro-apoptotic stimuli. The virus-infected cell growth slowed down by arresting the cell cycle at the G1/S phase and its cytoskeleton arrangement changed. This showed the target of the viruses is the cytoskeleton in particular the monomer Actin. The compoundtreated infected cells displayed a decrease in the $\mathrm{S}$ phase of the cell cycle and protect against cytoskeleton disruption [109].

Sophora species of Leguminosae family endowed with quinolizidine alkaloids exhibit anti-influenza activity. This is evident from the study of Dang et al. against H1N1 (A/Puerto Rico/8/34) virus and H3N2 Oseltamivir-sensitive virus (VR1679) which shows dihydroaloperine potent inhibitory activity with $\mathrm{EC}_{50}$ of 11.2 $\mu \mathrm{M}$ targeting NP. Interestingly, chemical modifications on the $\mathrm{N} 12$ and $\mathrm{C} 16$ positions of the aloperine scaffold improve the efficacy approximately about 5 -fold [140].

On more quinolizidine alkaloids, Matrine of Sophora flavescens has been proposed to be a target for the development of anti-influenza drugs. Yang et al. made the first attempt to utilize the molecular imprinted polymer technique, a non-biological method to identify the active components against the influenza virus. In this study, chloroform extracts of chlorogenic acid, phillyrin, matrine, oxymatrine, sophoridine, oxysophoridine, and aspirin were used as test compounds. Synthesized Oseltamivir molecularly imprinted polymer (OSMIP) was applied to liquid chromatography (LC) which exposed the retention time of 140 min used as template (OSMIP-LC column) for the selection of test compounds. The compound polarity was detected by OSMIP-LC column online and by electrospray ionization (ESI) MS offline shows Matrine with m/z 249 shows similar correlation like Oseltamivir. Further, in vitro study revealed matrine efficacy against H9N2 (A/Goose/Dalian/3/2001) in reducing cytotoxic effect and $\mathrm{HI}$ inhibition similar to Oseltamivir. Stereostructural resemblance consent matrine with Oseltamivir [141].

In silico studies of Gangopadhyay et al. [151] explain the alkaloid ormosinine might be a potential inhibitor of wild-type and mutant haemagglutinins of $\mathrm{H} 5 \mathrm{~N} 1$ virus.

\section{Phenolic compounds}

Phenolic compounds are the major secondary metabolite classified into several types as Phenylpropanoid, Tannin, Catechol, and Anthraquinone [173].

\section{Phenylpropanoid}

Phenylpropanoids comprise a wide diverse group of secondary metabolites which are synthesized from the primary metabolites, phenylalanine or tyrosine amino acids, either through the shikimate or the phenylpropanoid pathway. Phenylpropanoids can be categorized into five different groups as Flavonoids, Lignans, Phenolic acids, Stilbenes, and Coumarins [174].

\section{Flavonoid}

Flavonoids are the major group of Phenylpropanoids which comprise 8000 and more compounds [175]. The basic skeleton structure of flavonoids is C6-C3-C6 having a fused benzene ring designated as ring $\mathrm{A}$ and the pyran as ring $\mathrm{c}$, along with a phenyl group as ring $\mathrm{B}$ [176]. Flavonoids classified into three different classes as Flavonoids have 2-phenylbenzopyrans, Isoflavonoids with 3-benzopyrans, and neoflavonoids with 4benzopyrans [177]. Besides these, Biflavonoid [178] and prenylflavonoid [179] are the other classes included under flavonoid.

\section{Flavonoid (2-phenylbenzopyrans)}

Flavonoids are the natural compounds widely found in fruits, vegetables, flowers, seeds, nuts, spices, stems, chocolate, tea, and wine [180]. They have become an indispensable component in drug discovery research and have been ascribed promising resources for combating several viral diseases including influenza [181]. They are subdivided into different subgroups as flavones, flavanones, flavonols, flavanonol, flavan-3-ol, anthocyanin, and chalcones [182]. 


\section{Flavones}

Flavones are widely distributed in plants in various forms. Medicinal plants like Scutellaria baicalensis are reported to have the flavones Baicalin, 5, 7, 4'-trihydroxy-8-methoxyflavone (F36), isoscutellarein (5,7,8,4' tetrahydroxyflavone), wogonin, apigenin, baicalein, and chrysin shows anti-influenza activity. Apigenin and luteolin of Elsholtzia rugulosa, luteolin of Perilla frutescens, quercetin 3-rhamnoside (Q3R) of Houttuynia cordata, newly identified flavones of Sambucus nigra, and myricetin of Aronia melanocarpa are noted for their anti-influenza activities.

The herb Scutellaria baicalensis is enriched with flavones like baicalin. Ding et al. proved the efficacy of baicalin against influenza H1N1 (A/FM1/1/47) and H3N2 (A/Beijing/32/92) viruses by both in vitro and in vivo studies. The in vitro study provide $\mathrm{EC}_{50}$ values $43.3 \mathrm{lg} /$ $\mathrm{mL}$ and $104.9 \mathrm{lg} / \mathrm{mL}$ and the NI assay shows $\mathrm{IC}_{50}$ values $52.3 \mathrm{lg} / \mathrm{mL}$ and $85.8 \mathrm{lg} / \mathrm{mL}$ for the H1N1 and H3N2 viruses, respectively. These results explain baicalin as an effective neuraminidase inhibitor. Baicalin affected the virus budding in MDCK cells inoculated with the virus. Intravenous baicalin injection proved an increased survival rate with improved lung parameters in influenza virus-infected mice [132].

Neuraminidase enzyme also called sialidase cleaves the sialic acid link, between the virions and the host cell surface thereby maintaining the cycle of infection [183]. Nagai et al. checked the Sialidase inhibitory activity of flavonoids about 103 species using sodium pnitrophenyl-N-acetyl-z-D-neuraminate as substrate and found 5, 7, 4'-trihydroxy-8-methoxyflavone (F36) from the roots of Scutellaria baicalensis as potent inhibitor $\left(\mathrm{IC}_{50} \mu \mathrm{M}\right)$. Besides that, it blocked the infection and replication of the $\mathrm{A} / \mathrm{PR} / 8 / 34$ influenza virus [133].

The authors showed the sialidase inhibitory effect of isoscutellarein (5,7,8,4'-tetrahydroxyflavone) isolated from the leaf of Scutellaria baicalensis (Ki $41 \mu \mathrm{M})$ and observed replication inhibition in A/WSN/33 and A/PR/ 8/34 viral strains in MDBK cells $\left(\mathrm{IC}_{50} 20 \mathrm{pM}\right)$ and allantoic sac of an embryonated egg. The authors observed Isoscutellarein produce a similar effect as F36 and administered both into the mouse-adapted $\mathrm{A} / \mathrm{PR} / 8 / 34$. Intranasal administration disclosed F36 $(0.5 \mathrm{mg} / \mathrm{kg})$ complete prevention of virus proliferation, intraperitoneal administration showed F36 $(4 \mathrm{mg} / \mathrm{kg})$ reduced lung virus titers to $10^{<2}$, and oral administration explicit isoscutellarein (400 and $40 \mathrm{mg} / \mathrm{kg}$ ) significantly reduced lung virus titers [134].

The author continues further study by isolating 5,7 , 4'-trihydroxy-8-methoxyflavone (F36) from the roots of Scutellaria baicalensis and noted its effect in the reduction of H3N2 (A/Guizhou/54/89) and B (B/Ibaraki/2/85) viruses in MDCK after 4 hours of incubation. It reduces the virus yield by $50 \%$ at $20 \mu \mathrm{m}$ and $90 \%$ at $40 \mu \mathrm{m}$ in a dose-dependent manner. Fusion assay reported F36 was the inhibitor of virus fusion with the endosome/lysosome of the host cell. Intranasal 7 times $(3.5 \mathrm{mg} / \mathrm{kg})$ administration of F36 completely prevented the proliferation but did not inhibit proliferation of mouseadapted with virus inoculation from $18 \mathrm{~h}$ before to $54 \mathrm{~h}$ after [135]. The investigators perform the same mode of research work by applying F36 $(50 \mu \mathrm{m})$ on mouseadapted influenza virus A/PR/8/34 (A/PR8) and obtain a similar result like progeny inhibition and endosome/ lysosome membrane fusion inhibition [136].

Seong et al. investigated the antiviral role of wogonin isolated from Scutellaria baicalensis against influenza H1N1 (A/Puerto-Rico/8/34); seasonal H1N1 and H3N2; and $\mathrm{B}$ of Yamagata lineage (clinical influenza strains) and observed replication suppression in virus-adapted MDCK and A549 cell lines. Wogonin $(10 \mu \mathrm{g} / \mathrm{mL})$ treated influenza A virus-infected cells had significantly increased transcript levels of IFN- $\beta$ and IFN- $\lambda$ along with IFN downstream molecules MxA (myxovirus resistance gene A) and OAS (2-5' oligoadenylate synthetase). Furthermore, wogonin inhibited influenza virus-induced AMPK ( $5^{\prime}$ adenosine monophosphate-activated protein kinase) phosphorylation [137].

Hour et al. carried out in vitro and in silico studies using $\mathrm{MeOH}$, EtOAc, and chloroform extracts of Scutellaria baicalensis against pandemic $2009 \mathrm{H} 1 \mathrm{~N} 1$ (A/ Taiwan/CMUH/2009), seasonal H1N1 (A/Taiwan/ CMUH/2007, seasonal strains), seasonal H3N2 (Seasonal strains), and H1N1 (influenza A/Puerto Rico/8/34). EtOAc $\left(\mathrm{IC}_{50} 23.7\right.$ to $\left.27.4 \mu \mathrm{g} / \mathrm{mL}\right)$. The chloroform extracts $\left(\mathrm{IC}_{50} 14.16\right.$ to $\left.41.49 \mu \mathrm{g} / \mathrm{mL}\right)$ considerably decreased the virus proliferation than $\mathrm{MeOH}$ extract. The EtOAc ( $\mathrm{IC}_{50} 73.16$ to $487.40 \mu \mathrm{g} / \mathrm{mL}$ ) extract was remarkably noted for NA inhibition. HPLC analysis reported the flavone baicalin highly prevailed in the $\mathrm{MeOH}$ extract, high presence of apigenin in EtOAc, whereas in the EtOAc, and chloroform extracts were enriched with the flavones baicalein and chrysin. Further, in vitro and in silico studies are carried by using the flavones baicalin, apigenin, baicalein, and chrysin. In silico molecular simulation studies of these flavones against NA reveal baicalein potent interaction with NA1 active sites. In vitro plaque reduction assays also suggest baicalein effectively inhibit replication of pandemic $2009 \mathrm{H} 1 \mathrm{~N} 1$ $\left(\mathrm{IC}_{50}=0.02 \mu \mathrm{M}\right)$ and seasonal $2007 \mathrm{H} 1 \mathrm{~N} 1\left(\mathrm{IC}_{50}=0.018\right.$ $\mu \mathrm{M})$ [138].

Liu et al. isolated five flavonoids, namely apigenin (1), luteolin (2), apiin (3), galuteolin (4), and luteolin-3' -glucuronyl acid methyl ester (5) from the EtOAc extract of Elsholtzia rugulosa. The maximal non-cytotoxic concentration (MNCC) of the EtOAc extract with $\mathrm{IC}_{50} 55.56$ $\mu \mathrm{g} / \mathrm{mL}$ and its constituents showed inhibition of H1N1 
(A/PR/8/34), H3N2 (A/Jinan/15/90), and B (B/Jiangsu/ $10 / 2003)$. Among them, apigenin $\left(\mathrm{IC}_{50} 1.43 \mu \mathrm{g} / \mathrm{mL}\right)$ and luteolin $\left(\mathrm{IC}_{50} 2.06 \mu \mathrm{g} / \mathrm{mL}\right)$ exhibited the highest activities against $\mathrm{H} 3 \mathrm{~N} 2$ [96].

Perilla frutescens seeds contain four main polyphenolic compounds namely, rosmarinic acid-3-O-glucoside, rosmarinic acid, luteolin, and apigenin which were tested for the antiviral potential against recombinant virus H1N1 neuraminidase (rvH1N1 NA E.C. 3.2.1.18). Of these, the flavones luteolin $\left(\mathrm{IC}_{50} 8.4 \mu \mathrm{M}\right)$ and the rosmarinic acid (Phenolic acid with $\mathrm{IC}_{50}$ of $46.7 \mu \mathrm{M}$ ) showed potent NA activity and proved as noncompetitive inhibitors [118].

Choi et al. investigated the antiviral effects of the flavone quercetin 3-rhamnoside (Q3R) from Houttuynia cordata against $\mathrm{H} 1 \mathrm{~N} 1$ strain $\mathrm{A} / \mathrm{WS} / 33$ and observed the reduction of cytopathic effect in virus-infected MDCK cells. Pre-exposure of virus or Pre-inoculation of MDCK cells with Q3R did not alter its infectivity but Q3R role is appreciable only added at 1,2 , and $4 \mathrm{~h}$ after virus inoculation with the reduction in viral mRNA synthesis. This made the investigators conclude Q3R inhibits the initial stage of viral replication [104].

In vitro studies of Roschek B Jr et al. reveals the inhibitory efficiency of Sambucus nigra extract ( $\mathrm{IC}_{50} 252 \pm 34 \mu \mathrm{g} / \mathrm{mL}$ ) against H1N1(A/PR/8/34) and identified two flavonoid compounds $5,7,3^{\prime}, 4^{\prime}$-tetra-O-methylquercetin (1) and 5,7-dihydroxy-4-oxo-2-(3,4,5-trihydroxyphenyl) chroman-3-yl-3,4,5trihydroxycyclohexanecarboxylate (2) through direct binding assay and DART TOF-MS analysis. The authors urged these compounds were primarily responsible for anti-influenza activity by synthesizing flavanonol compound 1 and a flavanonol compound dihydromyricetin (corresponding 3hydroxyflavonone of 2) and observed H1N1 inhibition with $\mathrm{IC}_{50}$ value of $0.13 \mu \mathrm{g} / \mathrm{mL}$ and $2.8 \mu \mathrm{g} / \mathrm{mL}$. These compounds directly bind to the virus particles and prevent host cell entry and/or recognition similar to the antiviral drugs Oseltamivir and Amantadine [130].

Aronia melanocarpa fruits are rich in polyphenolic compounds which displayed wide antiviral activity against H1N1, H3N2, recombinant H1/PR8 expressing green fluorescent protein (rPR8-GFP), and influenza B virus. The Aronia mode of virucidal action is targeting the HA protein of H1N1 (A/Korea/01/2009) which is evident from the $\mathrm{HI}$ assay. Its flavone myricetin and the phenolic acid compound ellagic acid successfully inhibited the replication and did not show any cytotoxic effect against MDCK cells. The in vivo study exhibited myricetin and ellagic acid increase the survival rate by $50 \%$ and $37.5 \%$ of rPR8-GFP virus-infected mice [75].

\section{Flavonols}

Flavonols exist as Hyperoside in Azadirachta indica, Gossypetin and Kaempferol in Rhodiola rosea, and quercetin of Chaenomeles speciosa endowed as a promising agent for suppressing viral activities.

Ahmad et al. perform in silico docking studies by selecting Azadirachta indica active compounds nimbaflavone, rutin, and hyperoside along with drugs OMS, CBX, LGH, naproxen, BMS-883559, and BMS-885838 as ligands and the nucleoprotein structure [PDB ID:3RO5] as a receptor. All these ligands displayed perfect binding by interacting in the conserved residue (ASP302, TYR52, SER50, GLY288, SER376, and ARG99) of the receptor. But the best interaction was obtained from hyperosides along with the drugs LGH, naproxen, BMS-885838, and BMS-883559 [77].

Rhodiola rosea is a herbaceous plant used for food and medicine which contains constituents like flavonoids, phenylpropanoid and phenyl ethanol derivatives, and aliphatic glycosides. In this study, Jeong et al. isolated five flavonols (3, 5, and 9-11), and their structure-activity relationship (SAR) is compared with available flavonoids $(1,2,4,6-8$, and 12-14). All these compounds unveiled $\mathrm{NI}$ activity against Clostridium perfringens $\left(\mathrm{IC}_{50} 0.8\right.$ to $56.9 \mu \mathrm{M})$ and rvH1N1 $\left(\mathrm{IC}_{50} 2.2\right.$ to $\left.56.5 \mu \mathrm{M}\right)$. The antiviral activities of the compounds $1-6,8-12$, and14 had $\mathrm{EC}_{50}$ values of $30.2-99.1 \mu \mathrm{M}$ against $\mathrm{H} 1 \mathrm{~N} 1(\mathrm{~A} / \mathrm{PR} / 8 / 34)$ and 18.5-103.1 $\mu \mathrm{M}$ against H9N2 (A/Chicken/Korea/ MS96/96) in MDCK cells. Of these compounds, gossypetin (6) exhibited the most potent NI inhibitory activity $\left(\mathrm{IC}_{50}\right.$ values of 0.8 and $2.6 \mu \mathrm{M}$ ) and kaempferol (3) exhibited the highest anti-influenza activity against H1N1 and H9N2 $\left(\mathrm{EC}_{50}\right.$ values of 30.2 and $\left.18.5 \mu \mathrm{M}\right)$. The kinetic studies exposed all isolated flavonols act as noncompetitive inhibitors [127].

The flavonol quercetin of Chaenomeles speciosa exhibited significant dose-dependent DPPH radical scavenging activity with $\mathrm{IC}_{50} 3.82 \mu \mathrm{g} / \mathrm{mL}$. Quercetin of $5 \mu \mathrm{g} / \mathrm{mL}$ inhibits TNF- $\alpha$ by $33.14 \%$ and NO production [88].

\section{Flavanonols}

Flavanonol dihydromyricetin isolated from Sambucus nigra activated and induced the immune system to combat the influenza virus H1N1 (A/PR/8/34) through binding with virions and blocking entry and recognition of the host cell [130].

\section{Flavan-3-ol}

Flavan-3-ol compounds catechin, epicatechin (EC), epigallocatechin (EGC), epicatechin-3-gallate (ECG), epigallocatechin-3-gallate (EGCG), (-) epigallocatechin gallate (EGCg), and theaflavin digallate (TF3) have been reported in Camellia sinensis, (+)-catechin of Ephedrae herba, catechin-3-O-gallate of Polygonum cuspidatum, and gallocatechin-7-gallate (J10688) of Pithecellobium clypearia contribute significantly against influenza viruses. 
Tea is produced from the leaves of Camellia sinensis and classified into three types as non-fermented green tea, semi-fermented oolong tea, and fermented black and red tea [184]. The green tea is enriched with flavonol catechin. There are four main types of catechin predominantly found in green tea, namely epicatechin (EC), epigallocatechin (EGC), epicatechin-3-gallate (ECG), and epigallocatechin-3-gallate (EGCG) [185]. Differing from that, the black tea contains the polymerized catechins, namely theaflavins and thearugins [184]. Worldwide Green tea consumption is increasing due to the awareness of its health benefits [186]. Park et al. conducted a population-based study of school children in Kikugawa City, Japan, using the anonymous questionnaire survey and concluded the work that consumption of 1-5 cups/ day of green tea might prevent influenza infection among schoolchildren in a tea plantation area [187]. Matsumoto et al.'s studies explored green tea catechin prevents influenza among 197 health care workers [81].

Imanishi et al. studied the additional inhibitory effect of green tea extract (GTE) in MDCK cells infected with H1N1 (A/PR/8/34), H3N2 (A/Aichi/2/68), and B (B/ Singapore/222 (Sing) viruses and observed acidification of ELS (endosome and lysosome) inhibition through vital fluorescence microscopic studies. GTE exerts its effect within 5-15 min after infection and the authors observed the same inhibitory effects in GTE active catechin component (-) epigallocatechin (EGC) [82].

Green tea catechin compounds (-)-epigallocatechin gallate (EGCG), (-)-epicatechin gallate (ECG), and (-)-epigallocatechin (EGC) were analyzed for their antiinfluenza activities against HIN1 (Influenza A/Chile/1/ 83, H3N2 (A/Sydney/5/97) and B (B/Yamagata/16/88) viruses. EGCG $\left(\mathrm{EC}_{50} 22-28 \mu \mathrm{M}\right)$ and ECG $\left(\mathrm{EC}_{50} 22-40\right.$ $\mu \mathrm{M})$ showed more potent inhibition against the viruses than EGC (EC $\mathrm{E}_{50}$ 309-318 $\left.\mu \mathrm{M}\right)$, and also, more effective $\mathrm{HI}$ and NI activity and suppression of viral RNA synthesis in MDCK cells were noted in EGCG and ECG than in EGC [83].

The catechin (-)-epigallocatechin-3-O-gallate(EGCG) and EGCG-C-16 showed broad-spectrum anti-influenza activity against H1N1 (A/PuertoRico/8/34, A/Beijing/262/ 95, Yokohama/77/2008, Yokohama/63/2007, A/Yokohama/91/2008), H3N2 (A/Panama/2007/99), H5N2 (A/ Duck/HongKong/342/78), and B (B/Yamanashi/166/98/) viruses. EGCG-C-16 EC $\mathrm{EC}_{50}$ values range between 10 and 61 nM which were 7.1- to 44-fold lower than EGCG and $\mathrm{CC}_{50}$ value was $82 \mu \mathrm{M}$ which was 3.1 -fold lower than EGCG. Hence, EGCG-16 proved as a potent inhibitor with an SI value 2.2- to 14-fold greater than EGCG [84].

Nakayama et al. purified (-) epigallocatechin gallate (EGCg) and theaflavin digallate (TF3) from green and black tea and performed an inhibitory activity in opposition to H1N1 (A/Yamagata/120/86) and B (B/USSR/
100/83) virus-infected MDCK cells. Virus agglutination was observed when it was mixed with EGCg and TF3 even at a low concentration of $1.5 \mu \mathrm{M}$ and prevents its adsorption to MDCK cells. EGCg and TF3 at the concentration of $1-16 \mu \mathrm{M}$ bind to $\mathrm{HA}$, thereby preventing haemagglutination and obstructing its infectivity. However, EGCg $(>200 \mu \mathrm{M})$ and TF3 $(>100 \mu \mathrm{M})$ were toxic to MDCK cells [85]. In support of the above findings, Sahoo et al. perform in silico docking studies and concluded theaflavin as a potent natural inhibitor bind with the lowest energy $(-5.21 \mathrm{kcal} / \mathrm{mol})$ to $\mathrm{H} 1 \mathrm{~N} 1$ neuraminidase [86].

Mantani et al. observation reveal (+)-catechin(1.0-10.0 $\mathrm{mM}$ ) in the extract of Ephedra herba(EHext) inhibits acidification of ELS of H1N1(APR/8/34) at $1 \mathrm{~h}$. Effective inhibition of virus growth was observed when (+)-catechin (1.25-10.0 mM) treated within 10 min p.i. Surprisingly, $1 \mathrm{~h}$ or later, treatment exerted little and reversible inhibitory effect [97].

Chen et al. isolated and identified seven compounds 2methoxystypandrone (1), emodin (2), resveratrol(3), polydatin (4), emodin-8-O-beta-D-glucopyranoside (5), (E)-3, 5, 12-trihydroxystilbene-3-O-beta-D-glucopyranoside-2'-(3", 4", 5"'-trihydroxybenzoate) (6), and catechin-3-O-gallate (7) from the ethyl extract of Polygonum cuspidatum. These compounds were treated with H1N1-affected MDCK cells and revealed compounds 6 $\left(\mathrm{EC}_{50} 5.9 \mu \mathrm{M}\right)$ and $7\left(\mathrm{EC}_{50} 0.9 \mu \mathrm{M}\right)$ as potent inhibitors exhibiting low cytotoxicity to the host cells. The NI assay identified compounds 3,6 , and 7 with $\mathrm{IC}_{50}$ values of $129.8,44.8$, and 21.3 as active NA inhibitors [124].

Pithecellobium clypearia is rich in flavonoid compounds. Kang et al. isolated and identified the flavan-3ol compounds (2R,3R)-7-O-galloylplumbocatechin A (1), three known flavonoids (-)-5,3', $4^{\prime}, 5^{\prime}$-tetrahydroxyflavan-7-gallate (2), (+)-3,5,3',4',5'-penta-hydroxyflavan-7gallate (3), and (-)-7,4' -di-O-galloyltricetiflavan (4) from the leaves and twigs. These compounds were examined for NA assay, against H1N1 (A/PR/8/34), H3N2 (A/Sydney/5/97), and $B(B / J i a n g s u / 10 / 2003)$ viruses. The result indicated compounds $1\left(\mathrm{IC}_{50} 29.77 \pm 6.12 \mu \mathrm{g} / \mathrm{mL}\right)$ and 2 $\left(\mathrm{IC}_{50} 36.91 \pm 3.80 \mu \mathrm{g} / \mathrm{mL}\right)$ exhibited moderate activity against $\mathrm{H} 1 \mathrm{~N} 1$. All the compounds inhibited the expression of proinflammatory cytokines IL-6 or MCP-1 induced in H1N1 virus-adapted A549 cells. The structural verification of the compounds was performed using spectroscopic analysis [119].

From the leaves and twigs of Pithecellobium clypearia, $\mathrm{Li}$ et al. isolated flavan-3-ol gallocatechin-7-gallate (J10688) which acts as a novel CLK1 inhibitor with potent anti-influenza activity. In vivo studies performed by using intravenous administration of J10688 (30 mg/kg/ day) in H1N1-infected ICR mice which showed inhibition of pro-inflammatory cytokines IFN- $\gamma$, IL-6, TNF- $\alpha$, 
and IL-1 $\beta$, thereby preventing the viral infection and lung injury, and increased survival rate (91.67\%). In addition to this, dose-dependent treatment of J10688 stimulated lymphocyte proliferation, thereby cellular and humoral immune responsees were improved. In vivo cytotoxic studies performed by using J10688 against the strains H1N1 (A/PR/8/34), H3N2 (A/Sydney/5/97), and $B\left(B /\right.$ Jiangsu/10/2003) showed $E_{50}$ values $1.69,2.28$, and $23.18 \mu \mathrm{M}$, respectively. Hence, further anti-influenza studies were conducted by using H1N1-infected A549 cells where J10688 dosedependently $(3,10,30, \mu \mathrm{mol} / \mathrm{L})$ decrease viral $\mathrm{NP}$, M2, and RNA synthesis. Alternative splicing of the influenza virus M2 gene depends on the host cdc2like kinase 1 (CLK1). J10688 was an effective CLK1 inhibitor, by downregulating SC35 and SF2/ASF excessive phosphorylation and thereby controlling M2 mRNA alternative splicing [120].

\section{Anthocyanin}

Anthocyanin compounds from Ribes nigrum and redfleshed potato impart inhibitory activity against influenza viruses.

A study performed by Li et al. showed that using Ribes nigrum crude extracts with a $\mathrm{pH} 7.2$ inhibit H1N1 (A/ $\mathrm{PR} / 8 / 34)$ and $\mathrm{B}(\mathrm{B} / \mathrm{Gifu} / 2 / 73)$ plaque formation by $50 \%$ of $\mathrm{IC}_{50} 3.2 \mu \mathrm{g} / \mathrm{mL}$ and directly inactivated $99 \%$ of the virus by $10 \mu \mathrm{g} / \mathrm{mL}$ with a $\mathrm{pH} 2.8$. Post-exposure treatment of the extracts presented complete inhibition suppression in $\mathrm{H} 1 \mathrm{~N} 1(10-100 \mu \mathrm{g} / \mathrm{mL})$ which indicates the extract suppresses the late stage of virus growth. After 8-9 h of infection (both IVA and IVB) showing MDCK cells are treated with the extract of $100 \mu \mathrm{g} / \mathrm{mL}$ for $1 \mathrm{~h}$, and the virus titers in culture fluids show complete inhibition indicates extract inhibits the virus release [128].

The same authors and other investigators further investigated the crude extract and found anthocyanins as major constituents responsible for anti-influenza activity. Using TLC, the extract was fractionated into A to D and Anthocyanin D fraction was further fractionated into $\mathrm{A}^{\prime}$ to $G^{\prime}$. The fractions $D^{\prime}$ to $G^{\prime}$ produced potent antiinfluenza activity against $A$ and $B$ viruses. $E^{\prime}$ and $F^{\prime}$ exposed additive antiviral effects and identified as 3-Oalpha-L-rhamnopyranosyl-beta-D-glucopyranosyl-cyanidin and 3-O-beta-D-glucopyranosyl-cyanidin, and 3-Oalpha-L-rhamnopyranosyl-beta-D-glucopyranosyl-delphinidin and 3-O-beta-D-glucopyranosyl-delphinidin using HPLC. $F^{\prime}$ inhibits virus adsorption, release but not directly inactivate it [129].

Hayashi et al. bred anthocyanin-rich tetraploid potatoes cultivars of Solanum tuberosum ssp. tuberosum and S. tuberosum ssp. Andigena and red-fleshed potato (Inca Red) were selected. The purified anthocyanin powder along with the pigments pelanin (3-O-[6-O-(4-O-p- coumaroyl- $\alpha$-L-rhamnopyrano-syl)- $\beta$-D-glucopyranosyl]5-O- $\beta$-D-glucopyranosyl-pelargoni-din), pelargonidin, pelargonidin 3-p-coumaroylglucose with 5-glucose, and pelargonidin 3-p-coumaroylglucose with 5malonylglucose were tested for anti-influenza activity against $\mathrm{H} 1 \mathrm{~N} 1(\mathrm{~A} / \mathrm{PR} / 8 / 34)$ and $\mathrm{B}(\mathrm{B} / \mathrm{Gifu} / 2 / 73)$. The result revealed that anthocyanin powder showed the best inhibitory activity against $\mathrm{H} 1 \mathrm{~N} 1\left(\mathrm{IC}_{50} 48 \mu \mathrm{g} / \mathrm{mL}\right)$ and B $\left(\mathrm{IC}_{50} 54\right.$ $\mu \mathrm{g} / \mathrm{mL}$ ) than other pigments. The authors suggested that the antiviral activity of the potato anthocyanin is due to its additive or synergistic effect on other constituents including anthocyanin [139].

\section{Chalcones}

Chalcones bestowed with therapeutical properties have been noted for their anti-influenza activities. Recently chalcones isolated from Glycyrrhiza uralensis, Glycyrrhiza inflata, Thalassodendrin ciliatum, and Caesalpinia sappan showed strong anti-influenza activities.

Ryu et al. isolated 18 polyphenol compounds consisted of four chalcones, nine flavonoids, four coumarins and one phenylbenzofuran from the roots of Glycyrrhiza uralensis and evaluate their NA inhibitory activity. Of these the chalcone isoliquiritigenin $\left(\mathrm{IC}_{50} 9.0 \mu \mathrm{M}\right)$ and coumarin glycyrol $\left(\mathrm{IC}_{50} 3.1 \mu \mathrm{M}\right)$ showed strong inhibition on rvH1N1 NA (A/Ber-vig_Mission/1/18) and these are proved to be non competitive inhibitors [100].

From the acetone extract of Glycyrrhiza inflata, 8 chalcones were isolated, and their NA (H1N1, H9N2, H1N1 (WT), and H1N1 (H274Y)) inhibitory activities were accessed. Of these, compounds 3 (echinantin) and 6 (isoliquiritigenin) without the prenyl group exhibit strong inhibitory activity in viruses-infected 293T cells. Compound 3 (echinantin) and oseltamivir proved synergistic effects against NA of H274Y virus [99].

From the EtOAc extract of Thalassodendron ciliatum, Thalassodendrone (dihydrochalcone diglycoside), and 5 known phenolic compounds, namely asebotin, quercetin 3,7 diglucoside, protocatechuic acid, ferulic acid, and phydroxybenzoic acid were isolated and identified. These compounds were evaluated for anti-influenza activity against $\mathrm{H} 1 \mathrm{~N} 1$ (influenza A virus /WSN/33) and revealed asebotin $\left(\mathrm{IC}_{50} 2.00 \mu \mathrm{g} / \mathrm{mL}, \mathrm{CC}_{50} 3.36 \mu \mathrm{g} / \mathrm{mL}\right)$ inhibition and cytotoxic concentration were more than those of thalassodendrone $\left(\mathrm{IC}_{50} 1.96 \mu \mathrm{g} / \mathrm{mL}, \mathrm{CC}_{50} 3.14 \mu \mathrm{g} / \mathrm{mL}\right)$ [147].

Liu et al. isolated six NA inhibitor compounds that are brazilein, brazilin, protosappanin A, 3-deoxysappanchalcone, sappanchalcone, and rhamnetin from Caesalpinia sappan and evaluated their anti-influenza activity against $\mathrm{A} / \mathrm{PR} / 8 / 34$ (H1N1), A/Guangdong/243/72 (H3N2), and B/Jiangsu/10/ 2003 viruses. The results disclosed that the chalcone compounds 3-deoxysappanchalcone ( $\left.\mathrm{IC}_{50} 1.06\right)$ and sappanchalcone $\left(\mathrm{IC}_{50} 2.06 \mu \mathrm{g} / \mathrm{mL}\right)$ explained the highest inhibition activity against H3N2-infected MDCK cells [79]. 


\section{Isoflavonoid (3-benzopyrans)}

Isoflavonoid compounds build great attention in healthprotecting and health-promoting effects preferable to use in human medicine [188]. This class includes pterocarpans [189] and homoisoflavonoids [190].

\section{Pterocarpans}

From the methanol extract of Sophora flavescens, three pterocarpans and six flavanones were isolated and their NA inhibitory activity disclosed all the isolated compounds excluded the compound 3, showing inhibitory effects between 12 and $20 \mu \mathrm{M}$. Among these, pterocarpan 1 with $\mathrm{IC}_{50} 1.4 \mu \mathrm{M}$ displayed the best inhibition activity. Moreover, molecular docking studies of pterocarpan 1 with the receptor neuraminidase (PDB 1L7F) show the binding region nearer to the active site of the receptor [142].

\section{Homoisoflavonoid}

Homoisoflavonoids are a rare class of flavonoids present in few plant families like Fabaceae, Asparagaceae, Portulacaceae, Cucurbitaceae, and Polygonaceae [191]. Recently, it is reported in Caesalpinia sappan of the Fabaceae family disclosing potential anti-influenza activities.

Jeong et al. isolated 12 homoisoflavonoid compounds from the dried heartwood of Caesalpinia sappan and their antiviral efficacy against H1N1 (A/PR/8/34), H3N2 (A/Hong Kong/8/68), and H9N2 (A/Chicken/Korea/ MS96/96) describe the compounds are reversible noncompetitive inhibitors. Homoisoflavonoids with an unsaturated group like sappanone A (2) and brazilin (12) unveiled higher NA activity than saturated sappanone B (3). Hence, the investigators conclude that the $\alpha, \beta$ unsaturated carbonyl group in the A-ring is the main factor needed for NA inhibition [80].

\section{Biflavonoid}

Biflavonoids like Ginkgetin obtained from Ginkgo biloba inhibit the influenza virus sialidase. Miki et al. analyze the anti-influenza sialidase activity of ginkgetin, synthesized ginkgetin-sialic acid conjugates $(6 \mathrm{R}, 6 \mathrm{~S}, 7 \mathrm{R}, 7 \mathrm{~S}, 8 \mathrm{R}$, 8S, 9R, 9S), and 5, 7, 4'-trihydroxy-8-methoxyflavone (F36) against H1N1 (A/PR/8/34), H3N2 (A/Guizhou/54/ 89) and $B(B / I b a r a k i / 2 / 85)$ viruses. Ginkgetin inhibited sialidase of $\mathrm{H} 1 \mathrm{~N} 1$ and $\mathrm{H} 3 \mathrm{~N} 2$ with $\mathrm{IC}_{50}$ values of 55.00 and $9.78 \mu \mathrm{g} / \mathrm{mL}$ whereas the conjugate $8 \mathrm{R}$ (IC $505.50 \mathrm{lg}$ / $\mathrm{mL}$ and $0.82 \mathrm{lg} / \mathrm{mL}$ ) showed considerable inhibitory power. Ginkgetin acts as a sialidase inhibitor but it exerts a cytotoxic effect in MDCK cells, while the conjugates $8 \mathrm{R}$ and $8 \mathrm{~S}$ are empowered with low cytotoxic effect and high sialidase inhibition. The intranasal application of $8 \mathrm{R}$ and $8 \mathrm{~S}$ to the H1N1-infected mice reflected an increased survival rate of $75-78 \%$ at day 10 and $62.5-56 \%$ at day 21 [98].

\section{Prenylflavonoid}

In the study by Chiou et al., prenylflavonoid 8prenylkaempferol (8-PK) was isolated from the roots of Sophora flavescens and added into MDCK cells infected with H1N1 (A/PR/8/34) which significantly reduced RANTES accumulation along with nuclear factor- $k B$ $(\mathrm{NF}-\mathrm{kB})$ and interferon regulatory factor 3 (IRF-3) nuclear translocation in a dose-dependent manner. The investigators revealed the fact that both NF-kB and IRF-3 were essential for H1N1 RANTES production. The influenza virus-activated PI3K pathway and Akt phosphorylation were also attenuated along with the prevention of IkB degradation by 8 -PK. This PI3K-Akt pathway was essential for NF- $\mathrm{kB}$ - and IRF-3-mediated RANTES production [143].

\section{Prenylflavanones}

Ma et al. unveil that the six prenylflavanones, namely sophoraflavanones $\mathrm{M}(1)$ and $\mathrm{N}$ (2) glabranin (3) (2S)-7hydroxy-5-methoxy-8-prenylflavanone(4), (2S)-8-[2-(3hydroxyisopropyl)-5-methyl-4-hexenyl]-2'-methoxy-5,7, 4'-trihydroxyflavanone (5), and leachianone B (6) from the roots of Sophora flavescens showed inhibition against H1N1 (A/WSN/33/2009) except compound 5 (EC 5043.9 $\mu \mathrm{M})$ which produced moderate inhibitory activity [144].

\section{Lignans}

Lignans are the polymers of lignin comprising a large number of compounds. Compounds include arctiin, arctigenin in Arctium lappa, clemastanin B, and lariciresinol-4-O- $\beta$-D-glucopyranoside from Isatis indigotica which played a predominant role to restrict influenza viral infections.

Hayashi et al. explored two lignan components, arctiin and arctigenin, isolated from the fruits of Arctium lappa which exerted strong inhibitory effects on the replication of the H1N1 (A/NWS/33) virus. Further ongoing investigation reveals that arctigenin exhibited a 6- to 8 -fold lower $\mathrm{IC}_{50}$ value $\left(\mathrm{IC}_{50} 3.8-2.9 \mu \mathrm{M}\right)$ with minimum cytotoxic effect $\left(\mathrm{CC}_{50} 45 \mu \mathrm{M}\right)$ than arctin $\left(\mathrm{IC}_{50} 24-22 \mu \mathrm{M}\right.$, $\left.\mathrm{CC}_{50} 290 \mu \mathrm{M}\right)$ in virus-infected MDCK cells. Thus, it will be interesting to investigate and characterize arctigenin through the time of addition assay and progeny release assay. Surprisingly, arctigenin's best inhibitory effect was noted within immediate addition of virusinfected MDCK cells suggesting that it interacted with the early stage of viral replication but did not inhibit its cellular penetration. The addition of arctigenin, even after $8 \mathrm{~h}$ p.i. gives a scope that it inhibits viral progeny and release. The investigator's in vivo study explicitly explains that the oral administration of 
arctiin was converted into arctigenin in virus-infected mice along with more production of antibodies against the influenza virus. The authors observed the synergistic effect of arctiin and oseltamivir decreased the virus yield in both bronchoalveolar lavage fluids and lungs of infected mice [74].

Yang et al. isolated the lignan clemastanin from the root of Isatis indigotica and evaluated its antiviral inhibition efficiency against influenza viruses, respiratory syncytial virus (RSV), adenovirus 3 (ADV3), parainfluenza virus 3 (PIV3), enterovirus 71 (EV71), and human rhinovirus (HRV). The authors observed the compound inefficiency against all the viruses except influenza viruses (H1N1, H3N2, H6N2, H7N3, H9N2, and influenza B) with $\mathrm{IC}_{50} 0.087-0.72 \mathrm{mg} / \mathrm{mL}$. A distinct reduction of virus titer was observed only when the compound was added after viral incubation in the MDCK cell. The time course assay was performed using H1N1 (A/PR/8/34) and prominent inhibition was observed when clemastanin $\mathrm{B}$ treated $0-2 \mathrm{~h}$ after virus adsorption in the cell line, which suggested the compound target was at the early stage of replication. Moreover, this cell line unveiled the presence of viral RNP in their nucleus, which implies clemastanin B interferes with RNP export. Through a multi-passage experiment, the authors identified clemastanin B did not create drug resistance by the virus [107].

\section{Phenolic acid}

Phenolic acids are derivatives of benzoic acid and cinnamic acids. Benzoic acid derivatives include $p$-hydroxybenzoic acid, gallic acid, and ellagic acid, whereas cinnamic acid derivatives include rosmarinic acid [192].

The benzoic acid derivative compound 3, 4dihydroxybenzoic acid of Chaenomeles speciosa shows significant dose-dependent DPPH radical scavenging and NA inhibition activities against H1N1. It also significantly inhibits TNF- $\alpha$ and NO production [88].

The water-soluble polyphenol tannin is found in various plants and brings antiviral activity. Theisen et al. demonstrate anti-influenza activity of ethanol extract of Hamamelis virginiana bark against various strains of influenza A virus (H1N1 A/Puerto Rico/8/34, pandemic H1N1 A/Luxembourg/46/2009, seasonal H3N2 A/ Luxembourg/01/2005, H7N9 A/Anhui/01/2013) and found that gallic acid (phenolic acid), hamamelitannin (gallic acid derivative), tannic acid, and pentagalloylglucose (tannin) are the active part. The bark extract fractionated by ultrafiltration (UF) segregates low- and highmolecular-weight compounds. The low-molecularweight compounds of less than $500 \mathrm{~g} / \mathrm{mol}$ are gallic acid, epigallocatechin gallate, or hamamelitannin which exhibit neuraminidase inhibition but not hemagglutination, whereas high-molecular-weight tannin-containing extracts and tannic acid $(1702 \mathrm{~g} / \mathrm{mol})$ show inhibition of viral binding and neuraminidase [101].

Ellagic acid of Aronia melanocarpa inhibits replication without cytotoxic effect in HIN1 (A/Korea/01/2009)adapted MDCK cells and increased the $37.5 \%$ survival rate of rPR8-GFP virus-infected mice [75].

Perilla frutescens seeds contain rosmarinic acid, a cinnamic acid derivative, which shows potent NA activity with $\mathrm{IC}_{50}$ of $46.7 \mu \mathrm{M}$ and proved as noncompetitive inhibitors [118].

\section{Stilbenes}

Resveratrol, a low-molecular-weight stilbene compound isolated from the ethyl extract of Polygonum cuspidatum act as NA inhibitors with $\mathrm{IC}_{50}$ values of 129.8 [124].

\section{Coumarins}

Kurokawa et al. selected six antipyretic compounds, 7hydroxycoumarin (coumarin), 4-allylanisole, cinnamic acid ethylester, acetic acid cinnamylester, 2Xhydroxyacetophenone, and 2-hydroxycinnamic acid (cinnamyl derivatives) from the organic solvent-extractable fractions of Cinnamomum cassia and examined their antipyretic effects in $\mathrm{H} 1 \mathrm{~N} 1$ (A/PR/8/34)-infected mice that showed a remarkable reduction in rectal temperature. Further, four compounds, 7-hydroxycoumarin, 4-allylanisole, cinnamic acid ethylester, and acetic acid cinnamylester, suppressed the rise of interleukin- $1 \alpha$ production to the basal level and reduced its circulation in the serum. The presence of the ester bond is the main determiner for both antipyretic and interleukin-1 $\alpha$ suppression [90].

The above study brings out the fact that the coumarin compound, 7-hydroxycoumarin (7HC), reduced the proinflammatory cytokines along with antipyretic and interleukin suppression activities. The author Kurokawa and other investigators investigate $7 \mathrm{HC}$ in detail and explore $30 \mathrm{mg} / \mathrm{kg}$ oral administration of $7 \mathrm{HC}$ significantly reduces weight loss and virus production in the lung bronchoalveolar lavage fluid (BALF) of influenza-adapted mice. The author identified the suppression of proinflammatory and Th1 cytokine (IL-12 and interferongamma) results in the reduction of virus titer [91].

The coumarin glycyrol of Glycyrrhiza uralensis with $\mathrm{IC}_{50} 3.1 \mu \mathrm{M}$ showed strong inhibition on rvH1N1 NA and proved to be a non-competitive inhibitor [100].

\section{Tannin}

The hydrolyzable tannins strictinin found in Camellia sinensis comprised about $0-1.0 \%$ dry weight. The study of Saha et al. revealed that strictinin inhibits influenza A and $\mathrm{B}$ virus replication in a dose-dependent way by using MDCK cells. The influenza strains used for the study are A/PuertoRico/8/34 (H1N1), A/Memphis/1/71 (H3N2), A/Aichi/2/68(H3N2), A/duck/HK/313/4/78 
(H5N3), A/swine/Hokkaido/10/85(H3N2), A/WSN/33 (H1N1), and B/Lee/40. These studies bring the fact that strictinin acts directly with the viral particles and inhibit the early stage of viral entry and virus-induced hemifusion [87].

Haidari et al. studied pomegranate polyphenol extract (PPE) against H1N1 (A/USSR/90/77), H3N2 (A/Hong Kong/2/68, A/HK (H3N2)), and B (B/Harbin/07/94) viruses, which shows drastic proliferation inhibition without cytotoxicity in virus-adapted MDCK cells. H3N2induced agglutination of chicken is inhibited by PPE suggesting the target was viral attachment. PPE showed direct inhibitory and virucidal effects on the H3N2 virus which are observed through the RT-PCR technique. The single-cycle and multiple-cycle growth conditions indicated PPE affects viral replication but did not alter vRNP entry and translocation in the host cell. To identify active potential components from the extract, four polyphenol compounds, ellagic acid, caffeic acid, luteolin, and punicalagin, were selected and examined. Surprisingly, the tannin compound punicalagin plays similar activities, like PPE, and mimics the same effect. In addition to that, PPE produces a synergic effect when combined with oseltamivir [126]..

The tannin-rich components tannic acid and pentagalloylglucose of Hamamelis virginiana of $1702 \mathrm{~g} / \mathrm{mol}$ show inhibition of viral binding and neuraminidase [101].

\section{Catechol}

Hydroxytyrosol (HT) is one of the main phenolic components of Olea eurolaea belonging to the class of catechols produced a virucidal effect which was revealed in the study of Yamada et al. Hydroxytyrosol inactivates enveloped viruses including influenza A/Hokkaido/30/ 2000 (H1N1), A/Hokkaido/52/98 (H3N2), A/chicken/ Yamaguchi/7/04 (H5N1), and A/chicken/Yokohama/ aq55/01 (H9N2). HT did not show any cytotoxic effect on MDCK cells; it affected H9N2 virus NP protein synthesis and suppressed mRNA synthesis at 24 h.p.i. Electron microscopic analysis detects the structural disruption of the H9N2 virus by HT [113].

\section{Anthraquinone}

Aloe vera is a widely used herb of economical importance. In this study, two new anthraquinones, namely aloesaponarin-I (1) and aloesaponarin-II (2), were isolated from the roots. From aloesaponarin-I (1), six derivatives were obtained by the consecutive process like methylation (3), acetylation (4), and O-glycosyl $(5,6)$. As well as from aloesaponarin-II (2), a new derivative termed Tetra-O-acetyl- $\beta$-D-glucopyranosyl derivative obtained and these entire compounds experimented against H1N1 (A/Yucatán/2370/09, A/Mexico/ InDRE797/10) infection. All these compounds $\left(\mathrm{CC}_{50}>\right.$
$90 \mu \mathrm{M})$ did not exert any cytotoxic effect in MDCK cells. Virus replication inhibition analyzed by cytopathic effect reduction assay (CPE) noted compounds $3-\left(2^{\prime}, 3^{\prime}, 4^{\prime}, 6^{\prime}-\right.$ tetra-O-acetyl- $\beta$-D-glucopyranosyl-aloesaponarin-I and $\quad 3-\left(2^{\prime}, 3^{\prime}, 4^{\prime}, 6^{\prime}\right.$-tetra-O-acetyl- $\beta$-D-glucopyranosylaloesaponarin-II (7) against A/Yucatán/2370/09 $\left(\mathrm{IC}_{50}\right.$ of 30.77 and $13.70 \mu \mathrm{M})$ and $\mathrm{A} / \mathrm{Mexico} / \mathrm{InDRE797/10}\left(\mathrm{IC}_{50}\right.$ of 62.28 and $19.47 \mu \mathrm{M})$ reduction effect. Since other derivatives did not exhibit any antiviral effect, compounds 5 and 7 were taken for further studies. Plaque inhibition test using A/Yucatán/2370/09 strain noted the dosedependent addition of compound $5(50$ and $100 \mu \mathrm{M})$ had significantly reduced the virus titer more than compound 7. The time-of-addition experiment appraising the efficacy of two compounds yielded a 70\% reduction of virus titer at $6-10 \mathrm{~h}$ post-treatment [69].

\section{Glycosides}

Glycosides are active biological compounds reported in Albizia julibrissin, Panax quinquefolium, and Panax ginseng proved effective anti-influenza compounds.

Sun et al. isolated total saponin from the stem bark of Albizia julibrissin (AJSt) and fractionated it into AJS30, AJS50, AJS75, and AJS95. These compounds hemolytic activities and their adjuvant effect was reviewed. The compound AJSt, AJS50, AJS75, and AJS95 experienced minor hemolytic effects. The adjuvant effect of the compounds in the mice immunized with ovalbumin (OVA) and recombinant fowlpox virus vector-based avian influenza vaccine (rFPV) unveiled AJSt, AJS50, and AJS75 potent activities like enhancing concanavalin A (Con A), lipopolysaccharide (LPS), antigen-stimulated splenocyte proliferation, and serum antigen-specific IgG, IgG1, IgG2a, and IgG2b antibody titers. In-depth analysis of adjuvant action revealed AJS75 was the most potent adjuvant by inducing cellular and humoral response through stimulating cytokines and chemokines [68].

Dong et al. selected ginseng extracts (GE) and ginsenosides against the 2009 pandemic virus (A/Nanchang/ $8002 / 2009 \mathrm{H} 1 \mathrm{~N} 1$ (NC2)) and observed the effect in both in vitro and in vivo study. The mice infected with GENC2 showed an increased survival rate and minimum weight loss. Similarly, the pretreated ginsenoside- and NC2 (Rb1-NC2)-received mice show a remarkable survival rate. Meanwhile, the mice at 3 d.p.i. show a reduction in viral titer which revealed ginsenoside action against lethal lung damage. Hemagglutination assay confirms the interaction of ginsenoside with the HA, thereby interfering with the virus attachment. The authors explore sugar moieties of ginseng play a crucial role in the interaction with HA of the virus. Oligosaccharide binding assay confirms that ginsenoside prevents virus attachment with $\alpha 2-3^{\prime}$ sialic acid receptors on the 
host cell surface. Subsequently, it minimizes virus entry and thereof decreases the infection [116].

Chan et al. chose special types of ginsenoside (Re, Rg1, and PPT) of Panax ginseng and studied the effect of inflammation and apoptosis induced by the H9N2 (A/ Quail/Hong Kong/G1/97) virus. Human umbilical vein endothelial cells (HUVECs) were infected with H9N2 produce inflammation by inducing the chemokine IP-10 production. Ginsenoside PPT inhibits IP-10 production by regulating the micro RNA, miR-15b. Post-treatment of ginsenoside $\operatorname{Re}(50 \mu \mathrm{M})$ partially reduced the virusadapted apoptosis which denotes its cytoprotection and increased cell viability effect [115].

\section{Diarylheptanoids}

Diarylheptanoids are structurally distinctive compounds with diverse biological and pharmacological effects [193]. Recently, its anti-influenza effects have been reported in Alpinia officinarum and Curcuma longa.

From the rhizome of Alpinia officinarum, ten diarylheptanoids were isolated and their anti-influenza efficiency against H1N1 (A/PR/8/34) examined which provide the $\mathrm{EC}_{50}$ value of diarylheptanoids was lower than $\mathrm{CC}_{50}$ and MNCC (maximum non-cytotoxic concentration). The diarylheptanoids 7-4"'-hydroxy-3"methoxyphenyl)-1-phenyl-4E-hepen-3-one (3) and (5S)5-hydroxy-7-(4"-hydroxyphenyl)-1-phenyl-3-heptanone

(8) show the $\mathrm{EC}_{50}$ values $2.9 \pm 0.3 \mu \mathrm{g} / \mathrm{mL}$ and $0.7 \pm 0.3$ $\mu \mathrm{g} / \mathrm{mL}$ were lower than the control ribavirin $\mathrm{EC}_{50} 16.7 \pm$ $0.4 \mu \mathrm{g} / \mathrm{mL}$. Hence, the authors suggested diarylheptanoids 3 and 8 as a potent source of anti-influenza activity [70].

The authors continued the study by orally administering these two compounds 7-4"'-hydroxy-3"-methoxyphenyl)-1-phenyl-4E-hepen-3-one (AO-0002) and (5S)5-hydroxy-7-(4" -hydroxyphenyl)-1-phenyl-3-heptanone (AO-0011) three times daily to the H1N1 (A/PR/8/34)infected mice for 6 days after infection. AO-0002 (100 $\mathrm{mg} / \mathrm{kg}$ ) effectively reduced the bodyweight loss and enhanced the survival period of infected mice. AO-0002 (30 mg/kg, 30 and $100 \mathrm{mg} / \mathrm{kg}$ ) notably reduced the virus titer in the lung BALF of infected mice on days 3 and 6 after infection. AO-0011 did not exhibit the above activities; hence, the author selected AO-0002 for further in vitro analysis. AO-0002 effectively inhibited the infection of $\mathrm{H} 1 \mathrm{~N} 1$ (A/PR/8/34, oseltamivir-resistant A/PR/8/ 34, A/Bangkok/93/03), H3N2 (A/Ishikawa/7/82, A/ Fukushima/13/43), and B (B/Singapore/222/79, B/ Fukushima/15/93) viruses in MDCK cells. Plaque reduction assay revealed $\mathrm{AO}-0002$ was unable to interfere with the adsorption or invasion of the virus but dosedependently $(20-40 \mu \mathrm{g} / \mathrm{mL})$ suppressed the expression of viral antigen and mRNA synthesis [71].
Chen et al. evaluated the efficiency of curcumin against H1N1 (A/Puerto Rico/8/34) and H6N1 (A/ chicken/Taiwan/NCHU0507/99) which revealed no cytotoxic effect in virus-infected MDCK cells. Dosedependent addition of curcumin reduced viral replication. Specifically, $30 \mu \mathrm{M}$ of curcumin lessened $90 \%$ of virus yield. Time-of-addition experiments verified the direct inhibitory effect of curcumin. The mechanism was revealed by plaque reduction assay, which showed the early stage of inhibitory activity includes attachment prevention but not penetration. HA assay demonstrated curcumin possesses HA inhibition activity by interacting and interrupting the link between viruses HA and host cell receptors but not with the host RBC cell. In comparison with amantadine, curcumin did not evoke viral resistance [93].

Curcuma longa empowers a broad spectrum of antiviral activities. This creates interest for the investigators to investigate the presence of the substance in the herb. Recently, Dao et al. isolated 3 new (1-3) and 10 known (4-13) curcuminoids from the rhizome of Curcuma longa and performed neuraminidase inhibition assays against H1N1 (A/California/08/2009, A/Sw/Kor/CAH1/ 04, H274Y mutant) and H9N2 (A/Chicken/Korea/ O1310/2001). From the study, all compounds are proven as non-competitive inhibitors with significant NA activity, of which compounds 4, 5, and 13 showed the best potent ability [94].

\section{Isothiocyanate}

Isothiocyanate is one of the active ingredients of Wasabi japonica which shows a significant virucidal effect against the influenza virus when treated with the composition of $\mathrm{O} .1 \mathrm{SmL}$ isothiocyanate in addition to 0.05 $\mathrm{mL}$ virus. The content of isothiocyanate differs in different parts of the plant where the rhizome $(0.80$ $\mathrm{mol} \cdot \mathrm{mL}^{-1}$ ) had a high amount compared with the fibrous root and petiole [148].

\section{Conclusion}

Influenza remains a global threat. Even though it is under control, handling the pandemic situation remains a great challenge. Vaccine development and drug resistance coupled together to create a massive crisis in the difficult condition. To combat the problem, new drugs are necessary to practice. Keeping this view, alternative and traditional medicines provide new insights into the arrival of new drugs. This paper emphasizes an overview of the active ingredients of plants and their promising scientifically validated activity of the anti-influenza characteristics. Therefore, shortly, these active ingredients can be promoted for use as a new safe drug. A successful attempt can be claimed only when the clinical trial is appreciable. 


\section{Abbreviations}

ADV3: Adenovirus 3; AL-1: 14-a-Lipoyl andrographolide; AMPK: 5' adenosine monophosphate-activated protein kinase; APS: Astragalus polysaccharide; AJSt: Total saponin from the stem bark of Albizia julibrissin:

BALF: Bronchoalveolar lavage fluid; BCPS: Bupleurum chinense polysaccharides; BeA: Betulinic acid; $\mathrm{CC}_{50}$ : Half maximal cytotoxic concentration; CDC: Centers for Disease Control and Prevention; CEF: Chick embryo fibroblasts; CLK1: cdc2-like kinase 1; Con A: Concanavalin A; CPE: Cytopathic effect reduction assay; CVB3: Coxsackie virus B3; DAP: 14deoxy-11,12-dehydroandrographolide; DART TOF-MS: Direct analysis in real time mass spectrometry; diTPSs: Diterpene synthases; $\mathrm{EC}_{50}$ : Half maximal effective concentration; EC: Epicatechin; ECG: Epicatechin-3-gallate; EGC: Epigallocatechin; EGCg: (-) Epigallocatechin gallate:

EGCG: Epigallocatechin-3-gallate; EHext: Extract of Ephedra herba; ELS: Endosome and lysosome; ELISA: Enzyme-linked immunosorbent assay; ESI: Electrospray ionization; EtOAc: Ethyl acetate; EV71: Enterovirus 71; FDA: Food and Drug Administration; GE: Ginseng extract; GP: Panax ginseng polysaccharides; GTE: Green tea extract; HA: Hemagglutinin; 7HC: 7Hydroxycoumarin; HCP: Houttuynia cordata polysaccharides; HEF: Hemagglutinin esterase fusion; HeLa: Human epithelioid cervical carcinoma; HI: Hemagglutination inhibition assay; HIV: Human immunodeficiency virus; HPLC: High-performance liquid chromatography; HRV: Human rhinovirus; HT: Hydroxytyrosol; HUVECs: Human umbilical vein endothelial cells; IAV: Influenza A virus; IBV: Influenza B virus; IC: Inhibitory concentration; $\mathrm{I}_{50}$ : Half maximal inhibitory concentration; ICV: Influenza C virus; IDV: Influenza D virus; IFN: Interferon; IIV: Inactivated influenza vaccines; IRF-3: Interferon regulatory factor 3; IRPS: Isatis indigotica root polysaccharides; LAIV: Live attenuated influenza vaccines; LC: Liquid chromatography; LPS: Lipopolysaccharide; M1: Matrix protein; MDBK: MadinDarby bovine kidney cells; MDCK: Madin-Darby bovine canine kidney cells; $\mathrm{MeOH}$ : Methanol; MNCC: Maximal non-cytotoxic concentration; MxA: Myxovirus resistance gene A; MS: Mass spectroscopy; MTT assay: 3-(4,5Dimethylthiazol-2-yl)-2,5-diphenyltetrazolium bromide, a tetrazole) assay; NA: Neuraminidase; NEML: National essential medicines list; NF-KB: Nuclear factor-kB; NI: Neuraminidase inhibition assay; NIC: National Influenza Centers; NO: Nitric oxide; NP: Nucleoprotein or nucleocapsid protein; nsLTPs: Fetuinbinding non-specific lipid transfer protein; NTL: Narcissus tazetta lectin; OAS: 2-5' oligoadenylate synthetase; OSMIP: Oseltamivir molecularly imprinted polymer; OVA: Ovalbumin; 8-PK: 8-Prenylkaempferol; PA: Patchouli alcohol; PDB: Protein Data Bank; p.i.: Post-infection; PIV3: Parainfluenza virus 3; PPE: Pomegranate polyphenol extract; Q3R: Quercetin 3-rhamnoside; QIV: Quadrivalent inactivated vaccine; qRT-PCR: Real-time quantitative reverse transcription PCR; RANTES: Regulated upon Activation, Normal T cell Expressed and Secreted; rFPV: Recombinant fowlpox virus vector-based avian influenza vaccine; RSV: Respiratory syncytial virus; SAR: Structure-activity relationship; SIV: Swine influenza virus; SRB method: Sulforhodamine B assay (SRB); T\&CM: Traditional and Complementary medicine; TF3: Theaflavin digallate; TIV: Trivalent inactivated vaccine; TLC: Thin-layer chromatography; TOA: Time-of-addition assay; UF: Ultrafiltration; vRNP: Nuclear export of viral ribonucleoprotein; vRNP complex: Viral ribonucleoprotein complex; WHO: World Health Organization

\section{Acknowledgements}

Not applicable.

\section{Authors' contributions}

BDA collected and analyzed the data and wrote the manuscript. SR gave proper suggestions and approved the submission. Both authors contributed significantly to bring out this review and they have read and approved the manuscript.

\section{Funding}

Not applicable.

\section{Availability of data and materials}

All information provided in the manuscript is obtained from the references.

\section{Declarations}

Ethics approval and consent to participate Not applicable.

\section{Consent for publication}

Not applicable.

\section{Competing interests}

The authors declare that they have no competing interests.

Received: 29 December 2020 Accepted: 20 May 2021

Published online: 12 June 2021

\section{References}

1. Dacso CC, Couch RB, Six HR, Young JF, Quarles JM, Kasel JA (1984) Sporadic occurrence of zoonotic swine influenza virus infections. J Clin Microbiol 20(4):833-835. https://doi.org/10.1128/JCM.20.4.833-835.1984

2. Simonsen $L$ (1999) The global impact of influenza on morbidity and mortality. Vaccine 17:S3-S10. https://doi.org/10.1016/s0264-410x(99)00099-7

3. McCauley JW, Hongo S, Kaverin NV, Kochs G, Lamb RA, Matrosovich MN, Perez DR, Palese P, Presti RM, Rimstad E (2012) Orthomyxoviridae. In: King AMQ, Adams MJ, Carstens EB, Lefkowitz E (eds) Virus taxonomy, classification and nomenclature of viruses: ninth report of the International Committee on Taxonomy of Viruses. Elsevier, New York, pp 749-761

4. Ortiz-Baez AS, Eden JS, Moritz C, Holmes EC (2020) A divergent Articulavirus in an Australian gecko identified using meta-transcriptomics and protein structure comparisons. Viruses 12(6):613. https://doi.org/10.3390/v12060613

5. Bresee JS, Fry AM, Sambhara S, Cox NJ (2018) Inactivated influenza vaccines. In: Plotkin SA, Orenstein WA, Offit PA, Edwards KM (eds) Plotkin's Vaccines,7th edn. Elsevier, pp 456-488

6. Wang B, Loeb M (2019) Influenza Vaccines-Are They Efficacious or Not? In: Poland GA (ed) Vaccinations. Elsevier, pp 89-103

7. Long JS, Mistry B, Haslam SM, Barclay WS (2019) Host and viral determinants of influenza A virus species specificity.Nat. Rev Microbiol 17(2):67-81. https://doi.org/10.1038/s41579-018-0115-z

8. Pellett PE, Mitra S, Holland TC (2014) Basics of virology. In: Tselis AC, Booss J (eds) Handbook of clinical neurology, vol 123. Elsevier, pp 45-66

9. Zhai SL, Zhang H, Chen SN, Zhou X, Lin T, Liu R, Lv DH, Wen XH, Wei WK, Wang D, Li F (2017) Influenza D virus in animal species in Guangdong Province, southern China. Emerg Infect Dis 23(8):1392-1396. https://doi. org/10.3201/eid2308.170059

10. White SK, Ma W, McDaniel CJ, Gray GC, Lednicky JA (2016) Serologic evidence of exposure to influenza $D$ virus among persons with occupational contact with cattle. J Clin Virol 81:31-33. https://doi.org/10.101 6/j.jcv.2016.05.017

11. Asha K, Kumar B (2019) Emerging influenza D virus threat: what we know so far. J Clin Med 8(2):192. https://doi.org/10.3390/jcm8020192

12. Stohr K (2003) Overview of the WHO Global Influenza Programme. Dev Biol (Basel) 115:3-8

13. Jester B, Schwerzmann J, Mustaquim D, Aden T, Brammer L, Humes R, Shult P, Shahangian S, Gubareva L, Xu X, Miller J (2018) Mapping of the US domestic influenza virologic surveillance landscape. Emerg Infect Dis 24(7): 1300-1306. https://doi.org/10.3201/eid2407.180028

14. World Health Organization (2019) WHO Global Report on Traditional and Complementary Medicine. Available at: https://www.who.int/publicationsdetail/who-global-report-on-traditional-and-complementary-medicine-2019. Accessed May 3, 2020

15. Pan SY, Litscher G, Chan K, Yu ZL, Chen HQ, Ko KM (2014) Traditional medicines in the world: where to go next? Evid Based Complement Alternat Med 2014:1-4. https://doi.org/10.1155/2014/739895

16. Bouvier NM, Palese P (2008) The biology of influenza viruses. Vaccine 26 D49-D53. https://doi.org/10.1016/j.vaccine.2008.07.039

17. Yi Tsang N, Zhao LH, Wai Tsang S, Zhang HJ (2017) Antiviral Activity and Molecular Targets of Plant Natural Products Against Avian Influenza Virus. Curr Org Chem 21:1777-1804. https://doi.org/10.2174/138527282166617022 7120138

18. Laver WG, Webster RG (1976) Preparation and immunogenicity of a purified influenza virus haemagglutinin and neuraminidase subunit vaccine. Postgrad Med J 52(608):373-378. https://doi.org/10.1136/pgmj.52.608.373

19. Francis ME, King ML, Kelvin AA (2019) Back to the Future for Influenza Preimmunity-Looking Back at Influenza Virus History to Infer the Outcome of Future Infections. Viruses 11(2):E122. https://doi.org/10.3390/v11020122

20. Gao Q, Brydon EW, Palese P (2008) A seven-segmented influenza A virus expressing the influenza C virus glycoprotein HEF. J Virol 82:6419-6426. https://doi.org/10.1128/JVl.00514-08 
21. Stewart SM, Pekosz A (2012) The influenza C virus CM2 protein can alter intracellular $\mathrm{pH}$, and its transmembrane domain can substitute for that of the influenza A virus M2 protein and support infectious virus production. J Virol 86:1277-1281. https://doi.org/10.1128/JVI.05681-11

22. Matsuzaki $Y$, Sugawara K, Furuse $Y$, Shimotai $Y$, Hongo S, Oshitani H, Mizuta K, Nishimura H (2016) Genetic lineage and reassortment of influenza C viruses circulating between 1947 and 2014. J Virol 90:8251-8265. https://doi. org/10.1128/JVI.00969-16

23. Nakatsu S, Murakami S, Shindo K, Horimoto T, Sagara H, Noda T, Kawaoka Y (2018) Influenza C and D viruses package eight organized ribonucleoprotein complexes. J Virol 92:e02084-e02017. https://doi.org/10.1128/JVI.02084-17

24. Su S, Fu X, Li G, Kerlin F, Veit M (2017) Novel influenza D virus: epidemiology, pathology, evolution and biological characteristics. Virulence 8:1580-1591. https://doi.org/10.1080/21505594.2017.1365216

25. Hilleman MR (1954) Antigenic variation of influenza viruses. Annu Rev Microbiol 8:311-332. https://doi.org/10.1146/annurev.mi.08.100154.001523

26. Hill KL, Donelson JE (2001) Antigenic Variation. In: Brenner S, Miller JH (eds) Encyclopedia of Genetics. Academic Press, pp 79-81. https://doi.org/10.1 006/rwgn.2001.1458

27. Lamb A (2008) Influenza. In: Mahy BWJ, Van Regenmortel MHV (eds) Encyclopedia of Virology, 3rd Edition. Academic Press, pp 95-104. https:// doi.org/10.1016/B978-012374410-4.00654-3

28. Ditmar MF (2011) Infectious Diseases. In: Polin RA, Ditmar MF (eds) Pediatric Secrets, 5th Edition. Mosby, pp 354-422. https://doi.org/10.1016/B978-0-32306561-0.00011-2

29. Gerth HJ, Bauer KH, Steinitz H (1975) Is there evidence for antigenic drift of influenza C virus? Zentralbl Bakteriol Parasitenkd Infekt Hyg 231:47-56

30. Treanor J (2004) Influenza vaccine-outmaneuvering antigenic shift and drift. N Engl J Med 350:218-220. https://doi.org/10.1056/NEJMp038238

31. Centers for Disease Control and Prevention (2018) Immunization: The Basics definition of terms. Available at: https://www.cdc.gov/vaccines/vac-gen/imzbasics.htm. Accessed May 16, 2018

32. Ulmer J, Valley U, Rappuoli R (2006) Vaccine manufacturing: challenges and solutions. Nat Biotechnol 24:1377-1383. https://doi.org/10.1038/nbt1261

33. Palese $P$ (2006) Making better influenza virus vaccines? Emerg Infect Dis 12(1):61-65. https://doi.org/10.3201/eid1201.051043

34. Krammer F, Palese P (2015) Advances in the development of influenza virus vaccines. Nat Rev Drug Discov 14:167-182. https://doi.org/10.1038/nrd4529

35. Moa AM, Muscatello DJ, Turner RM, Maclntyre CR (2017) Epidemiology of influenza B in Australia: 2001-2014 influenza seasons. Influenza Other Respir Viruses 11(2):102-109. https://doi.org/10.1111/irv.12432

36. Halasa NB, Gerber MA, Berry AA, Anderson EL, Winokur P, Keyserling H, Eckard AR, Hill H, Wolff MC, McNeal MM, Edwards KM, Bernstein DI (2015) Safety and Immunogenicity of Full-Dose Trivalent Inactivated Influenza Vaccine (TIV) Compared With Half-Dose TIV Administered to Children 6 Through 35 Months of Age. J Pediatric Infect Dis Soc 4(3):214-224. https:// doi.org/10.1093/jpids/piu061

37. Zhang K, Wu X, Shi Y, Gou X, Huang J (2021) Immunogenicity of H5N1 influenza vaccines in elderly adults: a systematic review and meta-analysis. Hum Vaccin Immunother 17(2):475-484. https://doi.org/10.1080/21645515.2020.1777822

38. Centers for Disease Control and Prevention (2018). Seasonal Flu Shot. Available at: https://www.cdc.gov/flu/prevent/flushot.htm. Accessed May 16, 2018.

39. Wong SS, Webby RJ (2013) Traditional and new influenza vaccines. Clin Microbiol Rev 26(3):476-492. https://doi.org/10.1128/CMR.00097-12

40. Robertson CA, DiazGranados CA, Decker MD, Chit A, Mercer M, Greenberg DP (2016) Fluzone ${ }^{\circledast}$ High-Dose Influenza Vaccine. Expert Rev Vaccines 15(12):1495-1505. https://doi.org/10.1080/14760584.2016.1254044

41. Sullivan SJ, Jacobson R, Poland GA (2010) Advances in the vaccination of the elderly against influenza: role of a high-dose vaccine. Expert Rev Vaccines 9(10):1127-1133. https://doi.org/10.1586/erv.10.117

42. Overton ET (2012) Sometimes, more is better. J. Infect. Dis. 205:697-699

43. Tregoning JS, Russell RF, Kinnear E (2018) Adjuvanted influenza vaccines. Hum Vaccin Immunother 14(3):550-564. https://doi.org/10.1080/21645515.2 017.1415684

44. Centers for Disease Control and Prevention (2021). Live Attenuated Influenza Vaccine [LAIV] (The Nasal Spray Flu Vaccine) Available at:https:// www.cdc.gov/flu/prevent/nasalspray.htm. Accessed January 25, 2021

45. Clancy S (2008) Genetics of the influenza virus. Nature Education 1(1):83

46. Madsen A, Cox RJ (2020) Prospects and challenges in the development of universal influenza vaccines. Vaccines 8(3):361. https://doi.org/10.3390/va ccines8030361
47. Pica N, Palese P (2013) Toward a universal influenza virus vaccine: prospects and challenges. Annu Rev Med 64:189-202. https://doi.org/10.1146/a nnurev-med-120611-145115

48. Wei CJ, Crank MC, Shiver J, Graham BS, Mascola JR, Nabel GJ (2020) Nextgeneration influenza vaccines: opportunities and challenges. Nat Rev Drug Discov 19:239-252. https://doi.org/10.1038/s41573-019-0056-x

49. Houser K, Subbarao K (2015) Influenza vaccines: challenges and solutions. Cell Host Microbe. 17(3):295-300. https://doi.org/10.1016/j.vaccine.2016.08.01

50. Science.gov (2021) Oak Ridge, TN, US. https://www.science.gov/topicpages/ v/vaccine+manufacturing+capacity

51. McLean KA, Goldin S, Nannei C, Sparrow E, Torelli G (2016) The 2015 global production capacity of seasonal and pandemic influenza vaccine. Vaccine 34(45):5410-5413. https://doi.org/10.1016/j.vaccine.2016.08.019

52. Plans P (2008) Recommendations for the prevention and treatment of influenza using antiviral drugs based on cost-effectiveness. Expert Rev Pharmacoecon Outcomes Res 8:563-573. https://doi.org/10.1586/14737167. 8.6 .563

53. Shie JJ, Fang JM (2019) Development of effective anti-influenza drugs: congeners and conjugates - a review. J Biomed Sci 26:84. https://doi.org/1 0.1186/s12929-019-0567-0

54. Influenza (flu) antiviral drugs and related information (2020) US Food and Drug Administration, Rockville. https://www.fda.gov/drugs/informationdrug-class/influenza-flu-antiviral-drugs-and-related-information\#A pprovedDrugs. Accessed October 26,2020

55. Kohno S, Kida H, Mizuguchi M, Hirotsu N, Ishida T, Kadota J, Shimada J (2011) Intravenous peramivir for treatment of influenza A and B virus infection in high-risk patients. Antimicrob Agents Chemother 55(6):28032812. https://doi.org/10.1128/AAC.01718-10

56. Allen UD, Aoki FY, Stiver HG (2006) The use of antiviral drugs for influenza: recommended guidelines for practitioners. Can J Infect Dis Med Microbiol 17:273-284. https://doi.org/10.1155/2006/165940

57. Hayden FG, Sugaya N, Hirotsu N, Lee N, de Jong MD, Hurt AC, Ishida T, Sekino H, Yamada K, Portsmouth S, Kawaguchi K, Shishido T, Arai M, Tsuchiya K, Uehara T, Watanabe A, Baloxavir Marboxil Investigators G (2018) Baloxavir marboxil for uncomplicated influenza in adults and adolescents. N Engl J Med 379:913-923. https://doi.org/10.1056/NEJMoa1716197

58. Mishin VP, Patel MC, Chesnokov A, De La Cruz J, Nguyen HT, Lollis L, Hodges E, Jang Y, Barnes J, Uyeki T, Davis CT, Wentworth DE, Gubareva LV (2019) Susceptibility of influenza A, B, C, and D viruses to baloxavir (1). Emerg Infect Dis 25(10):1969-1972. https://doi.org/10.3201/eid2510.190607

59. Amarelle L, Lecuona E, Sznajder JI (2017) Anti-influenza treatment: drugs currently used and under development. Arch Bronconeumol 53:19-26. https://doi.org/10.1016/j.arbres.2016.07.004

60. De Clercq E (2006) Antiviral agents active against influenza A viruses. Nat Rev Drug Discov. 5:1015-1025. https://doi.org/10.1038/nrd2175

61. World Health Organization (2010) Pandemic (H1N1) 2009: antiviral drug resistance. Available at: https://www.who.int/csr/disease/swineflu/frequently_a sked_questions/ antivirals/resistance/en/. Accessed 29 Dec 2010.

62. Norberg P, Lindh M, Olofsson S (2015) Published sequences do not support transfer of oseltamivir resistance mutations from avian to human influenza A virus strains. BMC Infect Dis 15(1):1-7. https://doi.org/10.1186/s12879-0150860-9

63. Pal SK, Shukla Y (2003) Herbal medicine: current status and the future. Asian Pac J Cancer Prev. 4:281-288

64. Ganjhu RK, Mudgal PP, Maity H, Dowarha D, Devadiga S, Nag S, Arunkumar G (2015) Herbal plants and plant preparations as remedial approach for viral diseases. VirusDis 26(4):225-236. https://doi.org/10.1 007/s13337-015-0276-6

65. Mousa HA (2017) Prevention and treatment of influenza, influenza-like illness, and common cold by herbal, complementary, and natural therapies. J Evid Based Complementary Altern Med. 22(1):166-174. https://doi.org/1 $0.1177 / 2156587216641831$

66. Kamboj VP (2000) Herbal medicine. Curr Sci 78:35-51

67. Arora R, Chawla R, Marwah R, Arora P, Sharma R, Kaushik V, Goel R, Kaur A, Silambarasan M, Tripathi R (2011) Potential of complementary and alternative medicine in preventive management of novel H1N1 flu (Swine flu) pandemic: thwarting potential disasters in the bud. Evid Based Complement Altern Med 2011:1-16. https://doi.org/10.1155/2011/586506

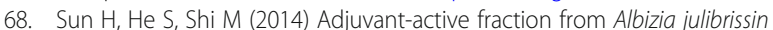
saponins improves immune responses by inducing cytokine and chemokine 
at the site of injection. Int Immunopharmacol 22(2):346-355. https://doi. org/10.1016/j.intimp.2014.07.021

69. Borges-Argáez R, Chan-Balan R, Cetina-Montejo L, Ayora-Talavera G, Sansores-Peraza P, Gómez-Carballo J, Cáceres-Farfán M (2019) In vitro evaluation of anthraquinones from Aloe vera (Aloe barbadensis Miller) roots and several derivatives against strains of influenza virus. Ind Crops Prod 132: 468-475. https://doi.org/10.1016/j.indcrop.2019.02.056

70. Sawamura R, Sun Y, Yasukawa K, Shimizu T, Watanabe W, Kurokawa M (2010) Antiviral activities of diarylheptanoids against influenza virus in vitro. J Nat Med 64(1):117-120. https://doi.org/10.1007/s11418-009-0372-2

71. Sawamura R, Shimizu T, Sun Y, Yasukawa K, Miura M, Toriyama M, Motohashi S, Watanabe W, Konno K, Kurokawa M (2010) In vitro and in vivo anti-influenza virus activity of diarylheptanoids isolated from Alpinia officinarum. Antivir Chem Chemother 21(1):33-41. https://doi.org/10.3851/ IMP1676

72. Chen JX, Xue HJ, Ye WC, Fang BH, Liu YH, Yuan SH, Yu P, Wang YQ (2009) Activity of andrographolide and its derivatives against influenza virus in vivo and in vitro. Biol Pharm Bull 32(8):1385-1391. https://doi.org/10.1248/ BPB.32.1385

73. Cai W, Li Y, Chen S, Wang M, Zhang A, Zhou H, Chen H, Jin M (2015) 14 Deoxy-11, 12-dehydroandrographolide exerts anti-influenza A virus activity and inhibits replication of $\mathrm{H} 5 \mathrm{~N} 1$ virus by restraining nuclear export of viral ribonucleoprotein complexes. Antiviral Res 118:82-92. https://doi.org/10.101 6/j.antiviral.2015.03.008

74. Hayashi K, Narutaki K, Nagaoka Y, Hayashi T, Uesato S (2010) Therapeutic effect of arctiin and arctigenin in immunocompetent and immunocompromised mice infected with influenza A virus. Biolo Pharm Bull 33(7):1199-1205. https://doi.org/10.1248/bpb.33.1199

75. Park S, Kim JI, Lee I, Lee S, Hwang MW, Bae JY, Heo J, Kim D, Han SZ, Park MS (2013) Aronia melanocarpa and its components demonstrate antiviral activity against influenza viruses. Biochem Biophys Res Commun 440(1):1419. https://doi.org/10.1016/j.bbrc.2013.08.090

76. Kallon S, Li X, Ji J, Chen C, Xi Q, Chang S, Xue C, Ma J, Xie Q, Zhang Y (2013) Astragalus polysaccharide enhances immunity and inhibits H9N2 avian influenza virus in vitro and in vivo. J Animal Sci Biotechnol 4(1):1-11. https://doi.org/10.1186/2049-1891-4-22

77. Ahmad A, Javed MR, Rao AQ, Husnain T (2016) Designing and screening of universal drug from neem (Azadirachta indica) and standard drug chemicals against influenza virus nucleoprotein. BMC complement Altern Med 16(1):18. https://doi.org/10.1186/s12906-016-1469-2

78. Zhang XQ, Chen HS (1989) Immuno-pharmacological effects of Bupleurum chinense polysaccharide. Chinese J Pharmacol Toxicol 3(1):30-33

79. Liu AL, Shu SH, Qin HL, Lee SM, Wang YT, Du GH (2009) In vitro antiinfluenza viral activities of constituents from Caesalpinia sappan. Planta Med 75:337-339. https://doi.org/10.1055/s-0028-1112208

80. Jeong HJ, Kim YM, Kim JH, Kim JY, Park JY, Park SJ, Ryu YB, Lee WS (2012) Homoisoflavonoids from Caesalpinia sappan displaying viral neuraminidases inhibition. Biol Pharm Bull 35(5):786-790. https://doi.org/10.1248/bpb.35.786

81. Matsumoto K, Yamada H, Takuma N, Niino H, Sagesaka YM (2011) Effects of green tea catechins and theanine on preventing influenza infection among healthcare workers: a randomized controlled trial. BMC Complement Altern Med 11(1):1-7. https://doi.org/10.1186/1472-6882-11-15

82. Imanishi N, Tuji Y, Katada Y, Maruhashi M, Konosu S, Mantani N, Terasawa K, Ochiai H (2002) Additional inhibitory effect of tea extract on the growth of influenza A and B viruses in MDCK cells. Microbiol Immunol 46(7):491-494. https://doi.org/10.1111/j.1348-0421.2002.tb02724.x

83. Song JM, Lee $\mathrm{KH}$, Seong BL (2005) Antiviral effect of catechins in green tea on influenza virus. Antiviral Res 68(2):66-74. https://doi.org/10.1016/j.antivira 1.2005.06.010

84. Kaihatsu K, Mori S, Matsumura H, Daidoji T, Kawakami C, Kurata H, Nakaya T, Kato N (2009) Broad and potent anti-influenza virus spectrum of epigallocatechin-3-O-gallate-monopalmitate. J Mol Genet Med 3(2):195-197. https://doi.org/10.4172/1747-0862.1000034

85. Nakayama M, Suzuki K, Toda M, Okubo S, Hara Y, Shimamura T (1993) Inhibition of the infectivity of influenza virus by tea polyphenols. Antiviral Res 21(4):289-299

86. Sahoo M, Jena L, Rath SN, Kumar S (2016) Identification of suitable natural inhibitor against influenza A (H1N1) neuraminidase protein by molecular docking. Genomics Inform 14(3):96-103. https:/doi.org/10.5808/Gl.2016.14.3.96

87. Saha RK, Takahashi T, Kurebayashi Y, Fukushima K, Minami A, Kinbara N, Ichitani M, Sagesaka YM, Suzuki T (2010) Antiviral effect of strictinin on influenza virus replication. Antiviral Res 88(1):10-18. https://doi.org/10.1016/ j.antiviral.2010.06.008

88. Zhang L, Cheng YX, Liu AL, Wang HD, Wang YL, Du GH (2010) Antioxidant, anti-inflammatory and anti-influenza properties of components from Chaenomeles speciosa. Molecules 15(11):8507-8517. https://doi.org/10.3390/ molecules 15118507

89. Hayashi K, Imanishi N, Kashiwayama Y, Kawano A, Terasawa K, Shimada Y, Ochiai H (2007) Inhibitory effect of cinnamaldehyde, derived from Cinnamomi cortex, on the growth of influenza $A / P R / 8$ virus in vitro and in vivo. Antiviral Res 74(1):1-8. https://doi.org/10.1016/j.antiviral.2007.01.003

90. Kurokawa M, Kumeda CA, Yamamura Jl, Kamiyama T, Shiraki K (1998) Antipyretic activity of cinnamyl derivatives and related compounds in influenza virus-infected mice. Eur J Pharmacol 348(1):45-51. https://doi.org/1 0.1016/S0014-2999(98)00121-6

91. Kurokawa M, Watanabe W, Shimizu T, Sawamura R, Shiraki K (2010) Modulation of cytokine production by 7-hydroxycoumarin in vitro and its efficacy against influenza infection in mice. Antiviral Res 85(2):373-380. https://doi.org/10.1016/j.antiviral.2009.11.001

92. Liao Q, Qian Z, Liu R, An L, Chen X (2013) Germacrone inhibits early stages of influenza virus infection. Antiviral Res 100(3):578-588. https://doi.org/10.1 016/j.antiviral.2013.09.021

93. Chen DY, Shien JH, Tiley L, Chiou SS, Wang SY, Chang TJ, Lee YJ, Chan KW, Hsu WL (2010) Curcumin inhibits influenza virus infection and haemagglutination activity. Food Chem 119(4):1346-1351. https://doi.org/1 0.1016/j.foodchem.2009.09.011

94. Dao TT, Nguyen PH, Won HK, Kim EH, Park J, Won BY, Oh WK (2012) Curcuminoids from Curcuma longa and their inhibitory activities on influenza A neuraminidases. Food Chem 134(1):21-28. https://doi.org/10.101 6/j.foodchem.2012.02.015

95. Li R, Liu T, Liu M, Chen F, Liu S, Yang J (2017) Anti-influenza A virus activity of dendrobine and its mechanism of action. J Agric Food Chem 65(18): 3665-3674. https://doi.org/10.1021/acs.jafc.7b00276

96. Liu AL, Liu B, Qin HL, Lee SM, Wang YT, Du GH (2008) Anti-influenza virus activities of flavonoids from the medicinal plant Elsholtzia rugulosa. Planta Med 74(8):847-851. https://doi.org/10.1055/s-2008-1074558

97. Mantani N, Imanishi N, Kawamata H, Terasawa K, Ochiai H (2001) Inhibitory effect of (+)-catechin on the growth of influenza A/PR/8 virus in MDCK cells. Planta Med 67(03):240-243. https://doi.org/10.1055/s-2001-12009

98. Miki K, Nagai T, Suzuki K, Tsujimura R, Koyama K, Kinoshita K, Furuhata K, Yamada H, Takahashi K (2007) Anti-influenza virus activity of biflavonoids. Bioorg Med Chem Lett 17(3):772-775. https://doi.org/10.1016/j.bmcl.2006.10.075

99. Dao TT, Nguyen PH, Lee HS, Kim E, Park J, Lim SI, Oh WK (2011) Chalcones as novel influenza A (H1N1) neuraminidase inhibitors from Glycyrrhiza inflata. Bioorg Med Chem Lett 21(1):294-298. https://doi.org/10.1016/j. bmcl.2010.11.016

100. Ryu YB, Kim JH, Park SJ, Chang JS, Rho MC, Bae KH, Park KH, Lee WS (2010) Inhibition of neuraminidase activity by polyphenol compounds isolated from the roots of Glycyrrhiza uralensis. Bioorg Med Chem Lett 20(3):971-974. https://doi.org/10.1016/j.bmcl.2009.12.106

101. Theisen LL, Erdelmeier CA, Spoden GA, Boukhallouk F, Sausy A, Florin L, Muller CP (2014) Tannins from Hamamelis virginiana bark extract: characterization and improvement of the antiviral efficacy against influenza A virus and human papillomavirus. PLoS one 9(1):e88062. https://doi.org/1 0.1371/journal.pone.0088062

102. Hayashi K, Kamiya M, Hayashi T (1995) Virucidal effects of the steam distillate from Houttuynia cordata and its components on HSV-1, influenza virus and HIV. Planta Med 61:237-241. https://doi.org/10.1055/s-2006-958063

103. Zhu H, Lu X, Ling L, Li H, Ou Y, Shi X, Lu Y, Zhang Y, Chen D (2018) Houttuynia cordata polysaccharides ameliorate pneumonia severity and intestinal injury in mice with influenza virus infection. J Ethnopharmacol 218:90-99. https://doi.org/10.1016/j.jep.2018.02.016

104. Choi HJ, Song JH, Park KS, Kwon DH (2009) Inhibitory effects of quercetin 3rhamnoside on influenza A virus replication. Eur J Pharm Sci 37(3-4):329333. https://doi.org/10.1016/j.ejps.2009.03.002

105. Wang X, Xue Y, Li Y, Liu F, Yan Y, Zhang H, Jin Q (2018) Effects of Isatis root polysaccharide in mice infected with $\mathrm{H} 3 \mathrm{~N} 2$ swine influenza virus. Res Vet Sci 119:91-98. https://doi.org/10.1016/j.rvsc.2018.04.012

106. Mak NK, Leung CY, Wei XY, Shen XL, Wong RN, Leung KN, Fung MC (2004) Inhibition of RANTES expression by indirubin in influenza virus-infected human bronchial epithelial cells. Biochem Pharmacol 67:167-174. https:// doi.org/10.1016/j.bcp.2003.08.020 
107. Yang Z, Wang Y, Zheng Z, Zhao S, Zhao Jl, Lin Q, Li C, Zhu Q, Zhong N (2013) Antiviral activity of Isatis indigotica root-derived clemastanin B against human and avian influenza $A$ and $B$ viruses in vitro. Int J Mol Med 31(4):867-873. https://doi.org/10.3892/ijmm.2013.1274

108. He J, Qi WB, Wang L, Tian J, Jiao PR, Liu GQ, Ye WC, Liao M (2013) Amaryllidaceae alkaloids inhibit nuclear-to-cytoplasmic export of ribonucleoprotein (RNP) complex of highly pathogenic avian influenza virus H5N1. Influenza Other Respi Viruses 7(6):922-931. https://doi.org/10.1111/ irv.12035

109. He J, Qi W, Tian J, Jiao P, Liu G, Zhang C, Liao M (2012) Amaryllidaceae alkaloids exhibit anti-influenza activity in MDCK cells, an investigation of Amaryllidaceae Alkaloids and MDCK cells insight. J Anim Vet Adv 11(14): 2485-2492. https://doi.org/10.3923/javaa.2012.2485.2492

110. Ooi VEC, Chan PKS, Chiu LCM, Sun SSM, Wong HNC (2014) Antiviral activity of Chinese medicine - derived phytochemicals against avian influenza A ( H5N1 ) virus. Hong Kong Med J 20(4):37-41

111. Ooi LS, Ho WS, Ngai KL, Tian L, Chan PK, Sun SS, Ooi VE (2010) Narcissus tazetta lectin shows strong inhibitory effects against respiratory syncytial virus, influenza A (H1N1, H3N2, H5N1) and B viruses. J Biosci 35:95-103. https://doi.org/10.1007/s12038-010-0012-8

112. Ooi LSM, Tian L, Su M, Ho WS, Sun SSM, Chung HY, Wong HNC, Ooi VEC (2008) Isolation, characterization, molecular cloning and modeling of a new lipid transfer protein with antiviral and antiproliferative activities from Narcissus tazetta. Peptides 29:2101-2109. https://doi.org/10.1016/j.peptides.2 008.08.020

113. Yamada K, Ogawa H, Hara A, Yoshida Y, Yonezawa Y, Karibe K, Nghia VB, Yoshimura H, Yamamoto Y, Yamada M, Nakamura K, Imai K (2009) Mechanism of the antiviral effect of hydroxytyrosol on influenza virus appears to involve morphological change of the virus. Antiviral Res 83(1): 35-44. https://doi.org/10.1016/j.antiviral.2009.03.002

114. Yoo DG, Kim MC, Park MK, Park KM, Quan FS, Song JM, Wee JJ, Wang BZ, Cho YK, Compans RW, Kang SM (2012) Protective effect of ginseng polysaccharides on influenza viral infection. PLoS One 7(3):e33678. https:// doi.org/10.1371/journal.pone.0033678

115. Chan LY, Kwok HH, Chan RW, Peiris MJ, Mak NK, Wong RN, Chan MC, Yue PY (2011) Dual functions of ginsenosides in protecting human endothelial cells against influenza H9N2-induced inflammation and apoptosis. J Ethnopharmacol 137(3):1542-1546. https://doi.org/10.1016/j.jep.2011.08.022

116. Dong W, Farooqui A, Leon AJ, Kelvin DJ (2017) Inhibition of influenza A virus infection by ginsenosides. PLoS One 12(2):e0171936. https://doi.org/1 0.1371/journal.pone.0171936

117. Ooi LS, Sun SS, Ooi VE (2004) Purification and characterization of a new antiviral protein from the leaves of Pandanus amaryllifolius (Pandanaceae). Int J Biochem Cell Biol 36:1440-1446. https://doi.org/10.1016/j.biocel.2004. 01.015

118. Ha TJ, Lee MH, Park CH, Kim Jl, Oh E, Pae SB, Park JE, Kim SU, Kwak DY (2018) rvH1N1 neuraminidase inhibitory activities of phenolics from Perilla frutescens (L.) and their contents in cultivars and germplasm. Plant Breed Biotech 6(4):404-412. https://doi.org/10.9787/ PBB.2018.6.4.404

119. Kang J, Liu C, Wang H, Li B, Li C, Chen R, Liu A (2014) Studies on the bioactive flavonoids isolated from Pithecellobium clypearia Benth. Molecules 19(4):4479-4490. https://doi.org/10.3390/molecules 19044479

120. Li C, Xu LJ, Lian WW, Pang XC, Jia H, Liu AL, Du GH (2018) Anti-influenza effect and action mechanisms of the chemical constituent gallocatechin-7gallate from Pithecellobium clypearia Benth. Acta Pharmacol Sin 39(12):19131922. https://doi.org/10.1038/s41401-018-0030-x

121. Yu Y, Zhang Y, Wang S, Liu W, Hao C, Wang W (2019) Inhibition effects of patchouli alcohol against influenza a virus through targeting cellular PI3K Akt and ERK/MAPK signaling pathways. Virol J 16(1):1-6. https://doi.org/1 $0.1186 /$ s12985-019-1266-X

122. Li YC, Peng SZ, Chen HM, Zhang FX, Xu PP, Xie JH, He JJ, Chen JN, Lai XP, Su ZR (2012) Oral administration of patchouli alcohol isolated from Pogostemonis Herba augments protection against influenza viral infection in mice. Int Immunopharmacol 12(1):294-301. https://doi.org/10.1016/j. intimp.2011.12.007

123. Wu H, Li B, Wang $X$, Jin $M$, Wang G (2011) Inhibitory effect and possible mechanism of action of patchouli alcohol against influenza A (H2N2) virus. Molecules 16(8):6489-6501. https://doi.org/10.3390/molecules16086489

124. Chen KT, Zhou WL, Liu JW, Zu M, He ZN, Du GH, Chen WW, Liu AL (2012) Active neuraminidase constituents of Polygonum cuspidatum against influenza A(H1N1) influenza virus. Zhongguo Zhong Yao Za Zhi 37(20): 3068-3073

125. Shoji M, Arakaki Y, Esumi T, Kohnomi S, Yamamoto C, Suzuki Y, Takahashi E, Konishi S, Kido H, Kuzuhara T (2015) Bakuchiol Is a Phenolic Isoprenoid with Novel Enantiomer-selective Anti-influenza A Virus Activity Involving Nrf2 Activation. J Biol Chem 290(46):28001-28017. https://doi.org/10.1074/jbc. M115.669465

126. Haidari M, Ali M, Casscells SW III, Madjid M (2009) Pomegranate (Punica granatum) purified polyphenol extract inhibits influenza virus and has a synergistic effect with oseltamivir. Phytomedine 16(12):1127-1136. https:// doi.org/10.1016/j.phymed.2009.06.002

127. Jeong HJ, Ryu YB, Park SJ, Kim JH, Kwon HJ, Kim JH, Park KH, Rho MC, Lee WS (2009) Neuraminidase inhibitory activities of flavonols isolated from Rhodiola rosea roots and their in vitro anti-influenza viral activities. Bioorg Med Chem 17(19):6816-6823. https://doi.org/10.1016/j.bmc.2009.08.036

128. Knox YM, Suzutani T, Yosida I, Azuma M (2003) Anti-influenza virus activity of crude extract of Ribes nigrum L. Phytother Res 17(2):120-122. https://doi. org/10.1002/ptr.1053

129. Knox YM, Hayashi K, Suzutani T, Ogasawara M, Yoshida I, Shiina R, Tsukui A, Terahara N, Azuma M (2001) Activity of anthocyanins from fruit extract of Ribes nigrum L. against influenza A and B viruses. Acta Virol 45(4):209-215

130. Roschek B Jr, Fink RC, McMichael MD, Li D, Alberte RS (2009) Elderberry flavonoids bind to and prevent H1N1 infection in vitro. Phytochemistry 70(10):1255-1261. https://doi.org/10.1016/j.phytochem.2009.06.003

131. Li Y, Jiang R, Ooi LS, But PP, Ooi VE (2007) Antiviral triterpenoids from the medicinal plant Schefflera heptaphylla. Phytother Res 21:466-470. https://doi org/10.1002/ptr.1962

132. Ding Y, Dou J, Teng Z, Yu J, Wang T, Lu N, Wang H, Zhou C (2014) Antiviral activity of baicalin against influenza $A(\mathrm{H} 1 \mathrm{~N} 1 / \mathrm{H} 3 \mathrm{~N} 2)$ virus in cell culture and in mice and its inhibition of neuraminidase. Arch Virol 159(12):3269-3278. https://doi.org/10.1007/s00705-014-2192-2

133. Nagai T, Miyaichi Y, Tomimori T, Suzuki Y, Yamada H (1990) Inhibition of influenza virus sialidase and anti-influenza virus activity by plant flavonoids. Chem Pharm Bull 38(5):1329-1332. https://doi.org/10.1248/cpb.38.1329

134. Nagai T, Miyaichi Y, Tomimori T, Suzuki Y, Yamada H (1992) In vivo antiinfluenza virus activity of plant flavonoids possessing inhibitory activity for influenza virus sialidase. Antiviral Res 19(3):207-217. https://doi.org/10.1016/ 0166-3542(92)90080-O

135. Nagai T, Suzuki Y, Tomimori T, Yamada H (1995) Antiviral activity of plant flavonoid, 5,7,4'-trihydroxy-8-methoxyflavone, from the roots of Scutellaria baicalensis against influenza A (H3N2) and B viruses. Biol Pharm Bull 18:295299. https://doi.org/10.1248/bpb.18.295

136. Nagai T, Moriguchi R, Suzuki Y, Tomimori T, Yamada H (1995) Mode of action of the anti-influenza virus activity of plant flavonoid, 5, 7, 4'trihydroxy-8-methoxyflavone, from the roots of Scutellaria baicalensis. Antiviral Res 26(1):11-25. https://doi.org/10.1016/0166-3542(94)00062-D

137. Seong RK, Kim JA, Shin OS (2018) Wogonin, a flavonoid isolated from Scutellaria baicalensis, has anti-viral activities against influenza infection via modulation of AMPK pathways. Acta Virol 62(1):78-85. https://doi.org/10.414 9/av_2018_109

138. Hour MJ, Huang SH, Chang CY, Lin YK, Wang CY, Chang YS (2013) Lin CW (2013) Baicalein, ethyl acetate, and chloroform extracts of Scutellaria baicalensis inhibit the neuraminidase activity of pandemic 2009 H1N1 and seasonal influenza A viruses. Evid Based Complement Alternat Med. https:// doi.org/10.1155/2013/750803

139. Hayashi K, Mori M, Matsutani Knox Y, Suzutan T, Ogasawara M, Yoshida I, Hosokawa K, Tsukui A, Azum M (2003) Anti influenza virus activity of a redfleshed potato anthocyanin. Food Sci Technol Res 9(3):242-244. https://doi. org/10.3136/fstr.9.242

140. Dang Z, Jung K, Zhu L, Lai W, Xie H, Lee KH, Huang L, Chen CH (2014) Identification and synthesis of quinolizidines with anti-influenza $A$ virus activity. ACS Med Chem Lett 5(8):942-946. https://doi.org/10.1021/ml500236n

141. Yang YJ, Li JY, Liu XW, Zhang JY, Liu YR, Li B (2013) A non-biological method for screening active components against influenza virus from traditional Chinese medicine by coupling a LC column with oseltamivir molecularly imprinted polymers. PLoS One 8(12):e84458. https://doi.org/1 0.1371/journal.pone.0084458.g001

142. Ryu YB, Curtis-Long MJ, Kim JH, Jeong SH, Yang MS, Lee KW, Lee WS, Park KH (2008) Pterocarpans and flavanones from Sophora flavescens displaying potent neuraminidase inhibition. Bioorg Med Chem Lett 18(23):6046-6049. https://doi.org/10.1016/j.bmcl.2008.10.033 
143. Chiou WF, Chen CC, Wei BL (2011) 8-Prenylkaempferol suppresses influenza A virus-induced RANTES production in A549 cells via blocking PI3K-mediated transcriptional activation of NF-KB and IRF3. Evid Based Complement Alternat Med 2011:920828. https://doi.org/10.1093/ecam/nep066

144. Ma JY, Zhao DR, Yang T, Liu D, Li RT, Li HM (2019) Prenylflavanones isolated from Sophora flavescens. Phytochem Lett 29:138-141. https://doi.org/10.101 6/j.phytol.2018.11.025

145. Hsieh CF, Chen YL, Lin CF, Ho JY, Huang CH, Chiu CH, Hsieh PW, Horng JT (2016) An extract from Taxodium distichum targets hemagglutinin- and neuraminidase-related activities of influenza virus in vitro. Sci Rep 6:36015. https://doi.org/10.1038/srep36015

146. Ibrahim AK, Youssef Al, Arafa AS, Foad R, Radwan MM, Ross S, Hassanean HA, Ahmed SA (2013) Anti-H5N1 virus new diglyceride ester from the Red Sea grass Thallasodendron ciliatum. Nat Prod Res 27(18):1625-1632. https:// doi.org/10.1080/14786419.2012.742082

147. Mohammed MM, Hamdy AH, El-Fiky NM, Mettwally WS, El-Beih AA, Kobayashi N (2014) Anti-influenza A virus activity of a new dihydrochalcone diglycoside isolated from the Egyptian seagrass Thalassodendron ciliatum (Forsk.) den Hartog. Nat Prod Res 28(6):377-382. https://doi.org/10.1080/14 786419.2013 .869694

148. Hu SQ, Hu G (2011) Extraction of isothiocyanate in Wasabi Japonica Matsum and its effects to influenza virus. In: 2011 IEEE International Symposium on IT in Medicine and Education, December 2011. Vol 1, Guangzhou, China, pp 45-48. https://doi.org/10.1109/TiME.2011.6130780

149. Cai Z, Zhang G, Tang B, Liu Y, Fu X, Zhang X (2015) Promising Anti-influenza Properties of Active Constituent of Withania somnifera Ayurvedic Herb in Targeting Neuraminidase of H1N1 Influenza: Computational Study. Cell Biochem Biophysics 72(3):727-739. https://doi.org/10.1007/s12013-015-05249

150. Hong EH, Song JH, Kang KB, Sung SH, Ko HJ, Yang H (2015) Anti-influenza activity of betulinic acid from Zizyphus jujuba on influenza A/PR/8 virus. Biomol Ther 23:345-349. https://doi.org/10.4062/biomolther.2015.019

151. Gangopadhyay AD, Ganguli SA, Datta AB (2011) Inhibiting H5N1 hemagglutinin with samll molecule ligands. Int J Bioinformatics Res 3:185189. https://doi.org/10.9735/0975-3087.3.1.185-189

152. Tiwari S (2008) Plants: A rich source of herbal medicine. J Nat Prod 1:27-35

153. Trouvelot S, Héloir MC, Poinssot B, Gauthier A, Paris F, Guillier C, Combier M, Trdá L, Daire X, Adrian M (2014) Carbohydrates in plant immunity and plant protection: roles and potential application as foliar sprays. Front Plant Sci 5: 592. https://doi.org/10.3389/fpls.2014.00592

154. Berg JM, Tymoczko JL, Stryer L (2002) In: Freeman WH (ed) Monosaccharides are aldehydes or ketones with multiple hydroxyl groups. Biochemistry, 5th edn, New York Available from: https://www.ncbi.nlm.nih. gov/books/NBK22547/. Accessed 20 Sep 2020

155. Shariatinia Z (2019) Pharmaceutical applications of natural polysaccharides. In: Hasnain MS, Nayak AK (eds) Natural Polysaccharides in Drug Delivery and Biomedical Applications. Academic Press, pp 15-57. https://doi.org/10.1016/ B978-0-12-817055-7.00002-9

156. Redasani VK, Bari SB (2015) Approaches for Prodrugs. In: Redasani VK, Bari SB (eds) Prodrug Design. Academic Press, PP, pp 33-49. https://doi.org/10.101 6/B978-0-12-803519-1.00004-0

157. Habtemariam S (2019) Medicinal Foods As Potential Therapies for Type-2 Diabetes and Associated Diseases. In: Habtemariam S (ed) Introduction to plant secondary metabolites-From biosynthesis to chemistry and antidiabetic action. Academic Press, pp 109-132. https://doi.org/10.1016/ B978-0-08-102922-0.00006-7

158. Ghosh S, Chisti Y, Banerjee UC (2012) Production of shikimic acid. Biotechnol Adv 30(6):1425-1431. https://doi.org/10.1016/j.biotechadv.2012.03.001

159. Bochkove DV, Sysolyatin SV, Kalashnikov Al, Surmachena IA (2011) Shikimic acid: review of its analytical, isolation and purification techniques from plant and microbial sources. J Chem Biol 5:5-17. https://doi.org/10.1007/s12154011-0064-8

160. Franzoni G, Trivellini A, Bulgari R, Cocetta G, Ferrante A (2019) Bioactive Molecules as Regulatory Signals in Plant Responses to Abiotic Stresses. In: Khan MIR, Reddy PS, Ferrante A, Khan NA (eds) Plant Signaling Molecules. Woodhead Publishing, pp 169-182. https://doi.org/10.1016/B978-0-12-8164 51-8.00010-1

161. Pott DM, Osorio S, Vallarino JG (2019) From central to specialized metabolism: an overview of some secondary compounds derived from the primary metabolism for their role in conferring nutritional and organoleptic characteristics to fruit. Front Plant Sci 10:835. https://doi.org/10.3389/fpls.201 9.00835

162. Ncube B, Van Staden J (2015) Tilting Plant Metabolism for Improved Metabolite Biosynthesis and Enhanced Human Benefit. Molecules 20(7): 12698-12731. https://doi.org/10.3390/molecules200712698

163. Shoker RM (2020) A Review Article: The Importance of the Major groups of Plants Secondary Metabolism Phenols, Alkaloids, and Terpenes. Int J Appl Sci Biotechnol 7(5):354-358. https://doi.org/10.31033/ijrasb.7.5.47

164. Singh B, Sharma RA (2015) Plant terpenes: defense responses, phylogenetic analysis, regulation and clinical applications. 3. Biotech 5:129-151. https:// doi.org/10.1007/s13205-014-0220-2

165. Perveen S (2018) Introductory Chapter: Terpenes and Terpenoids. In: Perveen S, Al-Taweel A (eds) Terpenes and Terpenoids. IntechOpen, London, UK, pp 1-13. https://doi.org/10.5772/intechopen.79683

166. Connolly JD, Hill RA (1991) Dictionary of terpenoids. Chapman and Hall, London

167. Wang G, Tang W, Bidigare RR (2005) Terpenoids as therapeutic drugs and pharmaceutical agents. In: Demain AL (ed) Zhang L. Humana Press, Natural Products Drug Discovery and Therapeutic Medicine, pp 197-227. https:// doi.org/10.1007/978-1-59259-976-9_9

168. Nguyen TD, MacNevin G, Ro DK (2012) De novo synthesis of high-value plant sesquiterpenoids in yeast. In: Hopwood DA (ed) Methods in enzymology, vol 517. Academic Press, pp 261-278. https://doi.org/10.1016/ B978-0-12-404634-4.00013-9

169. Jones B (2017) Diterpenoids: Types, Functions and Research. Nova Science Publishers, New York

170. Zerbe P, Chiang A, Dullat H, O'Neil-Johnson M, Starks C, Hamberger B, Bohlmann J (2014) Diterpene synthases of the biosynthetic system of medicinally active diterpenoids in Marrubium vulgare. Plant J 79(6):914-927. https://doi.org/10.1111/tpj.12589

171. Garg A, Sharma R, Dey P, Kundu A, Kim HS, Bhakta T, Kumar A (2020) Analysis of triterpenes and triterpenoids. In: Silva AS, Nabavi SF, Saeedi M, Nabavi SM (eds) Recent Advances in Natural Products Analysis. Elsevier, pp 393-426. https://doi.org/10.1016/B978-0-12-816455-6.00011-1

172. Richard T, Temsamani H, Cantos-Villar E, Monti JP (2013) Chapter Two Application of LC-MS and LC-NMR Techniques for Secondary Metabolite Identification. In: Rolin D (ed) Advances in botanical research, vol 67. Academic Press, pp 67-98. https://doi.org/10.1016/B978-0-12-397922-3.00002-2

173. Lattanzio V (2013) Phenolic compounds: introduction. In: Ramawat KG, Merillon JM (eds) Nat Prod. Springer-Verlag, Berlin, pp 1543-1580. https:// doi.org/10.1007/978-3-642-22144-6_57

174. Kumar S, Sumner B, Sumner LW (2020) Modern plant metabolomics for the discovery and characterization of natural products and their biosynthetic genes. In: Liu HW, Begley TP (eds) Compr Nat Prod III. Elsevier, pp 156-188. https://doi.org/10.1016/B978-0-12-409547-2.14807-3

175. Cheynier V (2012) Phenolic compounds: from plants to foods. Phytochem Rev 11:153-177. https://doi.org/10.1007/s11101-012-9242-8

176. Rauter AP, Ennis M, Hellwich KH, Herold BJ, Horton D, Moss GP, Schomburg I (2018) Nomenclature of flavonoids (IUPAC recommendations 2017). Pure Appl Chem 90(9):1429-1486. https://doi.org/10.1515/pac-2013-0919

177. Jan S, Abbas N (2018) Chapter 4-Chemistry of himalayan phytochemicals. In: Jan S, Abbas N (eds) Himalayan Phytochemicals Amsterdam. Elsevier, pp 121-166. https://doi.org/10.1016/B978-0-08-102227-6.00004-8

178. Kim HP, Park H, Son KH, Chang HW, Kang SS (2008) Biochemical pharmacology of biflavonoids: implications for anti-inflammatory action. Arch Pharm Res 31(3):265-273. https://doi.org/10.1007/s12272-001-1151-3

179. Chen X, Mukwaya E, Wong MS, Zhang Y (2014) A systematic review on biological activities of prenylated flavonoids. Pharm Biol 52(5):655-660. https://doi.org/10.3109/13880209.2013.853809

180. Amawi H, Ashby CR Jr, Tiwari AK (2017) Cancer chemoprevention through dietary flavonoids: what's limiting? Chin J Cancer 36(1):50. https://doi.org/1 0.1186/s40880-017-0217-4

181. Zakaryan H, Arabyan E, Oo A, Zandi K (2017) Flavonoids: promising natural compounds against viral infections. Arch Virol 162(9):2539-2551. https://doi. org/10.1007/s00705-017-3417-y

182. Panche AN, Diwan AD, Chandra SR (2016) Flavonoids: an overview. J Nutr Sci 5:e47. https://doi.org/10.1017/jns.2016.41

183. Glanz VY, Myasoedova VA, Grechko AV, Orekhov AN (2018) Inhibition of sialidase activity as a therapeutic approach. Drug Des Devel Ther 12:34313437. https://doi.org/10.2147/DDDT.S176220 
184. Yiannakopoulou EC (2012) Recent patents on antibacterial, antifungal and antiviral properties of tea. Recent Pat Antiinfect Drug Discov 7(1):60-65. https://doi.org/10.2174/157489112799829738

185. Chacko SM, Thambi PT, Kuttan R, Nishigaki I (2010) Beneficial effects of green tea: a literature review. Chin Med 5:13. https://doi.org/10.1186/17498546-5-13

186. Kosugi Y (2020) Green tea consumption In: World Green Tea Association Available at: https://www.o-cha.net/english/teacha/distribution/greentea3. html. Accessed 15 Aug 2020.

187. Park M, Yamada H, Matsushita K, Kaji S, Goto T, Okada Y, Kosuge K, Kitagawa $T$ (2011) Green tea consumption is inversely associated with the incidence of influenza infection among schoolchildren in a tea plantation area of Japan. J Nutrit 141(10):1862-1870. https://doi.org/10.3945/jn.110.137547

188. Malla A, Ramalingam S (2018) Chapter 11-Health Perspectives of an Isoflavonoid Genistein and its Quantification in Economically Important Plants. In: Grumezescu AM, Holban AM (eds) Role of Materials Science in Food Bioengineering. Academic Press, Cambridge, pp 353-379. https://doi. org/10.1016/B978-0-12-811448-3.00011-5

189. Foudah Al, Abdel-Kader MS (2017) Isoflavonoids. In: Justino J (ed) Flavonoids - From Biosynthesis to Human Health. UK IntechOpen Ltd, London, pp 61-95. https://doi.org/10.5772/intechopen.68701

190. Sharma V, Ramawat KG (2013) Isoflavonoids. In: Ramawat K, Mérillon JM (eds) Natural Products. Heidelberg, Springer, Berlin. https://doi.org/10.1007/ 978-3-642-22144-6 61

191. Mottaghipisheh J, Stuppner H (2021) A Comprehensive Review on Chemotaxonomic and Phytochemical Aspects of Homoisoflavonoids, as Rare Flavonoid Derivatives. Int J Mol Sci 22(5):2735. https://doi.org/10.3390/ ijms22052735

192. Vicente AR, Manganaris GA, Sozzi GO, Crisosto CH (2009) Nutritional quality of fruits and vegetables. In: Florkowski WJ, Prussia SE, Shewfelt SL, Brueckner B (eds) Postharvest handling: a systems approach, Food Science and Technology Series. Academic Press, Elsevier Inc, New York, USA, pp 57-106. https://doi.org/10.1016/B978-0-12-408137-6.00005-3

193. Sun DJ, Zhu LJ, Zhao YQ, Zhen YQ, Zhang L, Lin CC, Chen LX (2020) Diarylheptanoid: A privileged structure in drug discovery. Fitoterapia 142: 104490. https://doi.org/10.1016/jfitote.2020.104490

\section{Publisher's Note}

Springer Nature remains neutral with regard to jurisdictional claims in published maps and institutional affiliations.

\section{Submit your manuscript to a SpringerOpen ${ }^{\circ}$ journal and benefit from:}

- Convenient online submission

- Rigorous peer review

- Open access: articles freely available online

High visibility within the field

- Retaining the copyright to your article

Submit your next manuscript at $\boldsymbol{\nabla}$ springeropen.com 